\title{
DE VEROVERING
}

\section{DER \\ B A N D A - E I L A N D E N.}

De Banda-eilanden liggen tusschen $129^{\circ} 47^{\prime}$ en $130^{\circ} 31^{\prime}$ O. L. van Greenwich en $4^{\circ} 11^{\prime}$ en $4^{\circ} 39^{\prime}$ Z. B. ${ }^{1}$ en vormen eene schilderachtige groep. Hoewel slechts éene oppervlakte beslaande van nagenoeg 28 vierkante mijlen, voorzagen ze vroeger bijna alléén in de behoefte der voortreffelijke muskaatnooten en foelie.

In eene onuitgegeven beschrijving in Handschrift onder mij berustende en geschreven tusschen de jaren 1633-1639 worden wij op deze wijze met die eilanden bekend gemaakt 2 .

"De eijlanden van Banda sijn 5 in 't getal, daer' nooten ende foelij op groeijen, ende gepeupeleert zijn:

1. Groot Banda, tegenwoordich beseth met het fort Hollandija; op Lomthor is een huijs met 2 punten, een op Weijer, ende met drie steenen reduijten op Selamme, Denner ende Ourijen.

2. Neyra, beset met 3 sterckten bouen den anderen, genaemt Nassau, Belgica, beijde forten met 4 steenen punten, en 't bouenste een groote steenen reduijt, dat ouer de twee voorn. forten commandeert.

3. Poulo $A y$, beseth met een fort met 5 punten, Revengie genaemt.

4. Rosengeyn, beseth met 2 reduijten daer van een onbeseth blijft.

5. Poulo Ron, de Engelsen toebehoorende ende bij haer niet beseth

${ }^{1}$ Handleiding tot de Aardrijkskunde van Nederlands Oost-Ind. Bexittingen, uitgegeven door de Maatschappij: Tot Nut van 't Algemeen, 1843, bl. 297.

${ }^{2}$ Beschrijuinge van de eijlanden Banda so die geregeert sijn in de Jaren dat onse schepen daer eerst begonnen te negotijeren ende hoe deselve nu beseth sijn. 
wordt, wert derhaluen bij de Nederlanders met een corperaelschap soldaten voor den vijant bewaert ende woest gelaten 1 .

6. Goenong Apy ofte Vierbergh heeft voor deesen seer vruchtbaer ende bewoont geweest, maer sedert 't springen van voorschr. berch is woest geworden; dient nu maer om op de bequaemste plaatsen te betuijnen."

Reeds vroeg werden ze door onze zeevaarders bezocht. De later zoo beroemd geworden JACOB VAN HEEMSKERK sloot in het jaar 1599 reeds met de Bandanezen een verbond en kocht er eene groote hoeveelheid muskaatnooten en foelie 2. Volgens het bovengenoemd Handschrift "is woLPHERT "HARMANSZ., in het jaar 1602 met haer in accoort van handel getreden, "'t welk anno 1605 in Julij door den Admirael verfagen vernieut en"de beuesticht is, met eede van weedersijden. Onderwijlen is d'onsen al"daer, geen schepen sijnde, groote overlast van de Bandanesen tegen 't "accoort aangedaen, waerdoor anno 1609 bij den Admirael VERHOEUEN “een fort op Neyra versocht, 'twelk bij de inwoonderen toegestaen is; "ende in ' $t$ maeken van ditto fort hebben den Admirael met den raet; "van weedersijden vrindelijck vergadert sijnde om een goet accoort te "beramen, ouervallen, ende met 45 man vermoort, met meijninge alle de "Nederlanders te vernielen ende onder te brengen, doch wierden gestut. "Hierdoor sijn d' onsen geconstringeert geweest de waepenen tegen de "Bandanesen in handen te nemen; hebben het eijlant Neyra geheel onder "haer gehoorsaemheijt gebracht, het fordt voltrocken, hebben de Bandane"sen de souuereijniteijt van Banda de E. H. M. Heeren Staten opgedragen, "met eede aen de Comp ${ }^{e}$ verbonden; doch soo dickwijls als sij van alles "versien ende onse machten cleijn waeren, hebben den oorloch weeder tegen "ons aen genomen; wanneer onse macht haer te swaer ofte prouisije man"queerden maeckten vreede. Dit continueerden sij met vrede ende oorloch "den tijt van 12 jaeren, met verstijvinge van de Engelsen en Portugesen; "ende sijn door den Heer Generael coes in 't jaer 1621 alle de eijlan"den van Banda ouerwonnen, de inwoonderen die omtrent 15,000 sielen

1 Dit eiland heeft tot veel twistgeschrijf met Engeland aanleiding gegeven, het werd bij de vrede van Breda in 1667 voor goed aan ons afgestaan.

2 Handb. der Land- en Volkenkunde enz. van Nederl. Indï, door rOORDA vaN EYsINGA, 1841, I Boek, bl. 247. 
"sterck waren, sijn meest door den oorloch, armoede en gebreck vergaen, "seer weijnich sijn 't ontcomen ende werden als nu deselue landen met "andere natiën van wegen de E. Compe. gepopuleert. Men sustineert dat "van 15,000 sielen, daer dit lant meede bewoont is geweest, geen 1000 "ouergebleven sijn."

Van de oorspronkelijke bewooners dezer eilanden zullen er dus wel weinig meer overig zijn, want, zegt genoemde beschrijving, "als men de Ban"danesen begint te interrogeren van waer haerer, ouderen ende vooroude"ren afcomste is, soo sal men bemercken dat het maer een deel verban"nen ende van haere meesters ende ouders wechgeloopen slawen ofte ander"sints sijn geweest, die haer met eenich goet versonden hebben te han“delen, 'twelk sij opgesnapt ende geconsumeert hebbende, haer tot deese "plaetse begeuen hebben; in fijne dat men anders niet bespeuren kan, dan dat "haer ouders slauen geweest sijn, sommige die met haer meesters in Banda "gecomen sijn om te handelen ende, aldaer gestoruen, de slauen vrij gege"ven om aldaer oft op andere plaetsen te moogen woonen ende haer genut "soecken. Daar is qualijck een plaetse van de Caep Bona Esperansa tot “de viterste ofte oostelijckste eijlanden van Banda, ofte de natie van Banda "sijn daeraf gesproten, als van Caffers van Mousambique, Arabyanen, Per"syanen, van Cambaya, Cormandel, Bengula, Pegu, Atchynders, Mamora“uers [?], alderhande Malyen, Chinesen, Iauanen, Maccassers, Moluckanén, “Amboneesen ende diuerse mestise kinderen. Voorts sijn daer veel van deese "omleggende eijlanden, als Ceram, Papou, Kay, Aru, Teneber, Timor, "Solor, ende meest gecochte slauen; de vrouwen die sij noch dagelijcx "coopen, sijn meest Maleys, Javaens, Macassers, Bouttons, Bangaeys, oock "Moluckse, Amboyners, Cerams, Kay, Timor, maer de beste van Baaly. "Van alle dit onweetende gespuijs comen deese stoute onbeleefde tirannighe "Sabandaers ende Orangkaijs van Banda, daer af de geheele werelt weet, te "seggen: nu mogen de Hollanders haer wat helpen vermanen en sien of “wat meer goets van haer te verwachten staet, als in vorige tijden van haer "is geweest, etc."

De volgende bladen, door ooggetuigen geschreven, geven een getrouw verslag van de wijze waarop door de onzen, in het jaar 1616, onder de bevelen van den Admiraal JAN DIRKsz. 'T LAM, de verovering van Poeloe Ai, 
en die der gezamenlijke eilanden, onder die van den Gouverneur-Generaal JAN PIETERSz. COEN, in het jaar 1621, heeft plaats gehad, en bevatten bijzonderheden, die wij bij de Geschiedschrijvers niet geboekt vinden. Zie verder het belangrijke "Vertoogh van de staet der vereenichde Nederlanden in de quartieren van Oost-Indiën," ingediend door coen in het jaar 1623, in de Kronijk van het Historisch Genootschap te Utrecht, voor 1853, bladz. 95 : en seq.

P. A. LEUPE.

\section{OVER 'T INNEMEN VAN 'T EIJLAND GENAEMPT}

POULLU AY ANo 1616.

Alsoo bij d' Heer Generael GERART REYNs 't voorleden jaer eenen tocht was aengevangen op 't Eijlant Poullu ay ', den welcken niet en is gesuccedeert, 't selue heeft moeten verlaeten met verlies van een goede parthije voickx, ende veele gequeste; dan alsoo men de courragie van een goet begonnen werck daeromme niet en moet laeten berusten,

Soo is de saecke evenwel bij der handt genomen, ende door 't ouerlijden van de Heer Generael REYNs zaelicher, is bij den Raet van Indiën d' Heer JAN DIRRICKXsz. 'T LAM voor Commandeur-Generael gecorren, tot volvoeringhe van dit begonnen werck, waervan hem de brieuen op Amboynna behandicht sijn den $14^{\text {den }}$ Februarij $A^{\circ}$. 1616, bij cappiteijn wILLEM JACopsSEN, schipper op 't schip Veere, ende den vijftienden hebben wij al tsaemen soldacten ende bootgesellen den eet van getrouwicheijt gedaen.

D' Heer Commandeur heeft alle gereetschap laeten veerdich maecken die hem van noode soude moghen wesen. Ondertusschen is de vloote alhier bij den anderen vergaedert, ende in alles goede orde stellende is Out Seelant vertrocken naer Banda den 22 Februarij.

\footnotetext{
نولو أى Poeloe ay
} 
Den 28 Februarij is 't schip Veere ende de sloupe Enckhuijsen gecommandeert naer Banda te vertrecken, alsoo d' Heer Commandeur ende Raet geaduerteert waeren van twee ofte meer Ingelsche schepen die in see gesien waeren, vreesende sij aen Poullu ay den vijant eenich onderstant mochten doen, alwaer 't schip Veere ende sloupe gingen eruijssen.

Op den $8^{\text {sten }}$ Maerte is d' Heer Commandeur metten Raet ende vloote in Banda gearriueert, op de reede voor 't eijlant Neyra ende 't casteel Nassano, alwaer voor Gouverneur was d' Heer DIRRICK PIETERSSEN $\overline{\mathrm{VAN}}$ ZANDE.

Den $19^{\text {den }}$ Maerte zijn alhier op de reede 's nachts gearriueert den Rooden Leeuvo ende Soelen?, commende uwt Ternaden, gemonteert met drije hondert man, brochten tijdinghe, als dat d' Engelschen met vier schepen ende een sloupe voor Poullu ay ten ancker laeghen.

D' Heer Commandeur ende Raeden hiervan geaduiseert wesende, wiert ider belast hem gereet te maecken ende sijn op den 21 ditto vertrocken het Sallamsche gat wt naar d' Engelsche schepen.

Volghen de naemen van schepen $\overline{\mathrm{en}}$ sloup op den tocht.
't Waepen van Amsterdam.
't Schip Walcheren.
't Schip Veere.
Den Rooden Leenvo.
't Schip Nlissinghen.
't Schip Soelen?
't Schip Hooren.
Out Seelant.
't Schip de Hoope.
De Sloupe Enckhuijsen.

Op Neyra bleuen noch twee fregats die daer geduerelijck af ende aen voeren, om den vijant te krencken.

Op den $23^{\text {sten }}$ Maerte sijn onse schepen de eijlanden van Poullu ay seer genaedert, geresolueert sijnde, de Engelsche schepen van daer te slaen, waertoe gecommandeert waeren aen te tasten, als volcht:

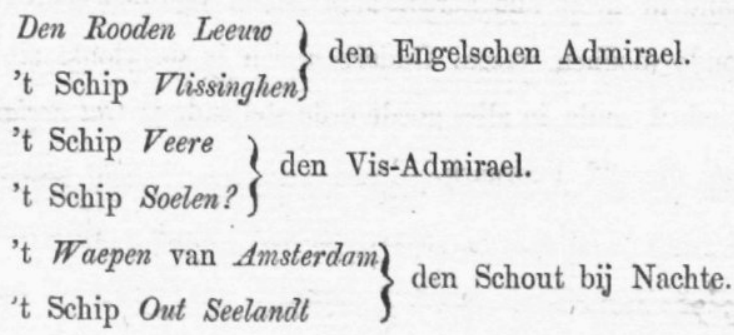




\section{$\left.\begin{array}{l}\text { 't Schip Walcheren } \\ \text { 't Schip Hooren }\end{array}\right\}$ den vierden man. \\ 't Schip de Hoope $\left.\begin{array}{l}\text { De Sloupe Enckhuijsen }\end{array}\right\}$ de Sloupe.}

De Engelschen met haere schepen op de reede liggende, onse vloote aldus siende aencommen, hebben haere anckers gelicht, maer meest laeten sitten, alsoo 't clipàchtighe gront is, ende sijn alsoo nae onse vloote gecommen, die haer strackx in eenen rijnck omcingelt hebben, al gereet sijnde om te slaen.

D' Heer steuen dansen? wesende op den Rooden Leeuro, heeft versocht dat den Engelschen Commandeur ouer comen soude; gaff voor antwoorde hij selue ouer comen soude, seggende, ick ben een dienaer van sijne Maijesteijt den Coninck van Engelant. Daar wierden diuersche schooten geschooten a la volle met scherp. Eijndelijck heeft hij gevraecht wie Admirael van de vloote was; daerop geantwoort wiert, JAN DIRRICKxsz. 'T LAM. Heeft begeert met hem te spreecken, ende sijn alsoo naer 't schip ' $t$ Waepen van Amsterdam geuaeren, alwaer de Commandeur op was. Bij den anderen gecomen sijnde, hebben van alles in 't breede gesproocken, belanghende de saecke van Poullu ay ende haere commissiën; voorder heeft hij aen d' onse te kennen gegeuen de sterckte $\bar{v}$ an plaetse om te landen en t' aprocheeren ende voorts van alles goet contentement gedaen, 't selue met eede bevestigende tot onse breder verseckeringhe, onder belofte met haere vier schepen te vertrecken ende alhier haere sloupe te laeten blijuen, tot dat Poullu ay verovert soude wesen, opdat wij van haere eeden ende woorden verseeckert sijnde, deselue soude laeten vaeren. Daer wiert menigen eerschoot geschooten, ende sijn op den $26^{\text {sten }}$ ditto van malcanderen geschieden. Den Rooden Leeun daer de Heer sTEUEN DANSEN op was, is met haerlieden vertrocken ende de vloot is weder op Neyra gecommen met de Engelsche sloupe.

D' Heer Commandeur metten Raet op Neyra sijnde, hebben alles wat ter saecke diende doen gereet maecken, voorder alles doen monsteren, soldaeten ende bootsgesellen, ende de artickelen voorgelesen. Eerst dat niemant hem vervoorderen en soude brandt te stichten in eenighe huijsen, voorder wat van nooten ofte foellie ende anders verouert wierde in 't gemeen soude 
gedeelt ofte betaelt worden, dan, (dat) niemant d'ordere van chrijchs gebruijck te buijten en soude gaen op lijffstraffe.

Volgen de naemen van ouericheijt $\overline{\text { en }}$ Cappiteijnen op desen tocht.

De Heer Commandeur JaN DIRRICKxsz 'T LAM, Veltouerste. STEUEN DANSSEN, Raet van Indiën. GISBRECHT VIAENEN, Raet van Indiën. ADRIAEN $\overline{\text { VAN }}$ DUSSEN, Ouerste van de artillerie ende amonitie. HEIJNDRICK DE JONGHE, Coopman, ouer de vivres.

PHILIPS SUERIUS, Secretaris.

\section{Cappiteijnen.}

Capt. GODSDEx.

Capt. LANCKHAER.

Capt. van HOEvEN.

Capt. Isebrant cornelissen, Schipper op 't Waepen van Amsterdam. Capt. WILLEM JACOPSSEN, Schipper op 't schip Veere.

Met een parthije Japponesen 'ende Chiawwers, wierden alle t' saemen geestimeert sterck te sijn acht hondert strijdbaere mannen.

Op den sesten April is d' Heer Commandeur metten Raet, met ses schepen, de sloup Enckhuijsen, ende twee fregats, vertrocken van Neyra naer Poullu ay. Int voorbij vaeren lanckx 't lant hebben d'inwoonders haer seer sterck verthoont in haer geweer als anders, schietende sommighe schooten naer de schepen, maer en deden gheen schade, sij lieten oock de Engelsche vlagge waeijen van haer casteel. Wij aldus lanckx 't lant vaerende sijn naer den middach dicht onder 't lant geanckert. 't Schip Out Seelant is voor 't casteel geanckert, was daertoe gecommandeert ende op toegemaeckt om 't casteel te beschieten, maer dede weinich voordeel, den schrick was 't meeste voor de swarte.

Den sevensten ditto is d' Heer Commandeur, metten daeghe, mette heele macht mette boots ende de schuijten gelant sonder ranconter te vinden. Bouen gecommen sijnde, 't welck maer een cleijnne hoochte en was, heeft hij de parthije in drije troupen gestelt, elcke troupe van drije compi, waer- 
van Capt. GoDsDex de voortocht hadde, de Japponesen en Chianvers gingen ter sijden, ende sijn alsoo gemarcheert in goede order door ' $t$ bosch naer haer casteel. Int marcheeren creghen de Japponesen twee hoofden van een parthije Bandannesen, die naert casteel meijnden te gaen.

Naer dat wij langhe tijt int volle geweer in ordere hadden gestaen, is in alle diligentie, ons dienstichs van de schepen aen lant gebracht, soo cruijt, lonte, loot, viures en groote parthije schans coruen, seijllen om tenten te maecken. Dit nu alles daer sijnde, soo sijn wij op den achtermiddach naer 't casteel getrokken op een musketschoot nae, ende aldaer het quartier nedergeslaeghen ende een gracht gemaeckt, diet sanderendaechs gemaeckt was, settende de schanscoruen lanckx den buijtenkant tot onse deffencie; de tenten waeren oock gemaeckt van de seijlen, soodat alle het volck daer onder conden gebercht worden, wesende aen de sijden van den vijant open, soo dat wij bequamelijgken sijn geweer conde gebruijken tegens eenen aenval, responderende op malcanderen, dewelcke ons dien nacht seer wel te passe quaemen.

De wacht wiert beset, elk op sijn quartier wtstellende veele schiltwachten, de officiers ende de ronde sijn seer sterck omme gegaen, de schiltwachten besoucken; die van binnen hebben seer geviert, licht brandende, met een gedurich getier ende speelen op haere tijfkens ende gomben [tifa's en gongen]. Naer den middernacht heeft het soo geweldich geregent, dat wij genootsaeckt waeren de uwtgestelde schildwachten te verlossen ende ons al tsaemen te begeuen in onse tenten, die ons dien nacht seer hoochelijk van noode waeren.

De achtsten ditto, des morghens naert slaen van reueijllie sijn alle de musketten ende roers gelost, met sulcken schoone vervolg ende sege dat het plaisier was om hooren, niettegenstaende den schrickelijcken regen die dien nacht was gestort; de wacht beset sijnde, heeft d' Heer Commandeur ende Raet ordere gestelt, om twee halue cortouwen aan lant te brengen van 't schip Veere, met haere toebehooren, 'twelck geschiet is, ende voorder in alle diligentie de battaria laten maecken.

Int maecken van battaria isser een parthije muskettiers gecommandeert dicht onder des vijants fort, die gedurichlijck daerop sargeerden om haer 't hooft binnen te doen houden, opdat d' onse te bequaemer mochten wer- 
cken. Sij hebben haer mannelijcken verthoont in haer geweer op de mueren, oock sonder ophouden groot geruchte gemaeckt op de gomben ende tijfkens, ondertusschen dapper geschooten met bassen, roers ende musketten, op onse battaria, quetsende sommighe persoonen, onder anderen wiert doot geschooten den vendrich MYroode, die hem wat buijten begeuen hadde roeppende tegen eenen ouerlooper oochske genaemt.

Ondertusschen d' Heer Commandeur, die geen ruste en hadde, maer geduerichlijck sijns persoons was presenterende, van d' een plaetse op d'ander, isser scherpe wacht gehouden, parthijen in 'tboseh gesonden, voorders alles gevoordert wat noodich was, tot voorderijnghe van de saeeke, met een goede resolutie, de battaria gestelt, 't casteel beschooten sijnde, met een mannelijcke courragie te bestormen.

De twee halve cortouwen aen lant sijnde, ende in hare affuijten staende sijn omtrent de battaria gebracht voor in 't bosch, alwaer op den achter middach twee schooten mede geschooten wierden, op den houck van haer casteel in de presentie van Hr. Commandeur en de Capt. LANCKHafr, die den constabel vereerde met ses reaelen, om dat hij soo wel hadde geschooten.

Den neghensten April, de battaria ten deele volmaeckt sijnde, de schans corven, geuolt is door last van d' Heer Commandeur ende Raet belast de stucken te stellen. Ondertusschen hebben de Capiteijns ende alle officieren elck in sijne beroepinghe haer seer sorchfuldichlijeken gequeten, de vijant belettende alle middelen om ons te beschaedigen, die haer altemets buijten haer fort als binnen waeren verthoonende, maer geen voordeel siende bleuen ter plaetse daer sij waeren.

De battaria gemaeckt, de stucken gestelt, is bij ADRIAEN vaN DUSSEN, ouerste van de artillerije, belast aen den constabel dien nacht op haer casteel te schieten, 'twelck geschiet is tot 10 a 12 schooten. Die van binnen maeckten groot getier van schreeuwen tot omtrent nae middernacht, daer naer en wierden sij niet gehoort, 'twelk d' onse veroorsaeckte niet meer te schieten, de wacht versterckende, verhoopende den vijant eenen uwtval soude doen; maer ten volchde niet.

Den thienden ditto, was alles gereet gemaeckt om te stormen, maer alsoo wij geen vijant en vernoomen nochte hoorden, waeren daerouer verwondert. Somwijllen hoorden wij noch eenen elop ofte twee op de gomme 
slaen maer ten duerde niet, waerouer een jongman, ondercuijper van 't schip Veere, hem verstoutte naer 't fort te gaen. Niet vernemende, is ouergeclommen, heeft er niemant inne geuonden als een oude vrouwe die de gomme geslaeghen hadde om ons te abuseeren, terwijllen sijlieden alle vluchten.

Desen jongman is dadelijck bij de wacht ende in 't quartier gecommen, 'tselve ruchtbaer gemaeckt. De Heeren altsaemen hieruan geaduerteert sijnde, hebben, de Compe in ordere gestelt sijnde, naer toe gemarcheert, het quartier wel beset. Capt. Hallin, hoewel het hem niet toe en quam isser van ter sijden ingetrocken, waer ouer groote woorden vielen, hij heeft sijn vendel laeten vlieghen ende die van Bandannesen die noch woeijen verworpen. Gisbrecht vianen was mede op den muer als een soldaet in 't luijt rouppen ende schelden, 't voas sonder perijckel men schoot daer niet.

D' Heer Commandeur metten Raet hebben d' andere compagniën belast voort te trecken door 't bosch, naer 't hooghe fort genaempt, 'twelk een stercke plaetse is. Sij is seer priculeus om op te comen. Aldaer gecomen sijnde en hebben niemant vernomen, soo dat den vijant met vrouw $\overline{e n}$ kinderen ende alles wat sij hadden mede connen slepen gevlucht met correcorren, prauwen als anders naer Lonthor ende Poullu ron 1.

De parthijen tot alhier gecommen sijnde ende niet connende vernemen, sijn wedergekeert naer 't quartier, uwtsendende seeckere parthijen in 't bosch om te vernemen ende gaen besichtighen, maer en hebben niet vernomen, soo is elck bij de sijne gekeert, voorts goede wacht bestelt.

Gedurende onsen tocht alhier sijn wij altsaemen seer wel versien geweest door Sr. HEYNDRICK DE JONGHE, coopman op 't schip Veere, van eeten ende drincken, soodat wij dieshaluen de Heeren moeten bedancken.

Wat belanght het verouerde eijlant van Poullu ay, is een schoon heerlijck lant vol alderleij schoone vrnchten, principalijcke die costelijcke nootenboomen die de weerde niet te priseeren en sijn, maer en heeft geen vers waeter. 't Casteel nae haere wijse lach seer propijs gemaeckt, met vier punten ende gordijnnen, beslooten met twee poorten, van binnen vol huijsen, daar veele schoone waeterpotten, saggou, oude clappessen, porceleijn ende andere huijsraet in gevonden wiert, voorder een parthije metaele bassen, oock een groot

\footnotetext{
1 Poeloe Rhun فولو )ون
} 
stuck van hout gemaeckt. Te platte lande lacht soo schoon al ofte de voetpaeden geveecht hadden geweest, stondt oock vol huijsen, elk hebbende sijnnen thuijn. Naer dat wij verstaen hebben waerender voor ons compste op dit eijlant ouer de 1800 sielen, daer waeren oock veel bocken ende hoenderen. In somma om cort te maecken het is een cleijn paradijs van vruchten ende schoonheijt, is groot twee mijllen in 't ronde, maer en heeft geen reede om schepen te ligghen.

D' Heer Commandeur, met die van Raede ende Capp ${ }^{t}$ tsaemen vergaedert, verblijt sijnde ouer dese subijtte heerlijeke victorie, hebben Godt daer ouer gedanckt ende in alle minsaemheijt tsaemen gegeten ende gedroncken; voorts is ieder gecommandeert te trecken naer sijn schipsboort, aen lant laetende 'tgheene noodich was, mitsgaders de twee halue cortouwen. De schepen sijn weder vertrocken naer Neyra.

Ick hebbe hier vooren verhaelt van 't gheene ons mette Engelsche is gepasseert die haere logie op 't eijlandt waeren houdende, ende aldaer noch drije mannen hadden gelaeten, die naer 't veroueren van 't lant mette sloup gehaelt soude werden, hoe sij d' onse gewaerschout hadden van de gelegenheijt van 't fort, van haere stucken, mede de plaetsen die de Bandannesen met voetangels beset hadden ende voorts 't gheene ons schaedelijck soude moghen wesen, waerachtich beuonden.

Voorder is bij d' Heer Commandeur ende Raeden op Poullu ay geadmitteert als Luijttenant-Gouverneur ADRIAEN VAN DER DUSSEN, hebbende een Comp' soldaten, beneffens 't Gouvernement, tot Luijttenant GERRIT verdelft, Vendrich anthony schamman. Als noch een compe. waerouer commandeerde Capt. JaN vaN hoEven, tot Luijttenant Jacob sтоск, Vendrich JaN wILLEMsz. goumalue. Aldus was 't lant versien van twee wel gemonteerde compagnien. Tot coopman Sr. HEYNDk̀ICK DE JONGHE, assistenten aNthoNy caen, ende christoffel vaN LAER.

Den Coninck .... van Chiaur [op Halmaheira] met sijne huijsvr. ende kinderen, mitsgaeders alle de Chiaucers, vrouwen ende kinderen, die door last van den Generael ende Raeden van Indiën van haer lant gelicht waeren, meestendeel tegens haeren danck, (:int lichten $\overline{\text { van }}$ selue verlooren d' onse 18 à 19 mannen:), mede op Poullu ay gecommen ende noch eenighe Gusuratten ende Mardickers, soo getrout als ongetroude, dic ten deele bij Capt. willem JA- 
copssz. schipper op 't schip Veere -waren verouert op de custe van Java met eenen goeden pris. Voorts eenige vrije lieden, commende van Solor, alsoo 't casteel ende comptoir aldaar gelicht was, naer 't gevoelen van veele hadde beeter gelaeten geweest. Aldus heeft men het eijlant beginnen te peupeleeren ende vermenichfuldighen.

Hier boven hebt gij verstaen $\overline{v a n}$ gevluchte Bandannesen die door haer subijt vertreck haere corre-corren ende prauwen soo vervult hadden; onder weghen op 't waeter sijnde, door den wint die hem verhieff, soo wij verstaen hebben, ook ten deele de doode lichamen die gestrang [? d. i. gestrand] waeren, ouer de vier hondert sielen verdroncken.' Dus sijn dese cloeckmoedighe Bandannesen die 't jaer te vooren ons volck soo mannelijcken hadden afgeslaegen, gevlucht, die de geheele Indiën door bekent en geroempt waeren voor de clouckste backeleijers ${ }^{1}$, gelijck sij ook waeren op haere wijse, maer en hadden geen verstant van halue cortouwen te verwachten. Wij en hebben nooijt connen verstaen hoe veel dooden ofte gequeste dat sijlieden hadden. Van d' onse waren 8 a 9 doot en een parthije gequest.

D' Heer Commandeur ende Raeden op Poulli-ay alles in goede orde gestelt hebbende, hebben haer afschiet genomen, ende sijn mette fregats naer Neyra gevaeren. Aldaar gecommen sijnde hebben de Engelschen sloupe ontslaeghen ende is naer Poullu ay gevaeren, alwaer sij noch een goede parthije nooten hadden liggen, die sij ten deele heeft connen laeden, de reste heeft den Luijttenant-Gouverneur naer hem genomen, ick meene ten proffijte van de compagnie. Sij wierden in de loogie gebracht.

De sloupe Enckhuijsen was afgevoordert met brieuen naer Ambon ende Java, om de tijdinghe te brenghen $\overline{v a n}$ victorie.

De Engelsche sloupe gereet sijnde ende naer de drije voor verhaelde mannen vernomen, hebbende deselue niet connen becommen, sijn vertrocken naer Poullu ron. Aldaer niet vernemende waer deselue souden moghen gebleuen wesen, presumeerden de Bandannesen haar gedood hadden.

Op den derden Meije isser een generalen peijs gemaeckt met die van Lonthor, Sallamme, Poullu ron ende Rosageyne, ende is ter wedersijden beedicht ende beuesticht, waardoor wij noch goede parthije nooten ende foellie chregen.

1 بركلاى Berkalai, vechten. 
Dit aldus gepasseert ende alles in goede ordre gesteld sijnde, heeft de Heer Commandeur 'T LAM, de t'overzicht ende regeringhe ten hoochsten gerecommandeert aen d' Heer Gouverneur DIRRICK PIETERSSEN vaN zANDE ende ADRIAAN VĀ DUSSEN, Luijttenant-Gouverneur over Poullu ay ende is vertrocken naer Amboïnna.

\section{CONQUESTE VAN HET EILANT BAND A EN IN WAT MANIEREN HET SELUIGE IS VEROUERT ANNO 1621.}

Memorie van de compste vañ Heer Generael JAN PIETERsz. coEN metten Raet ende geheele vloote, in d' eilanden van Banda voort casteel Nassauro, liggende op 't eijlant Neyra, omme 't lant van Lonthor, Sallamme, Poul$l u$ ron ende Rosageyne te veroueren met haere apphedentiën.

Den 12 Februarij is d' Heer Generael, d' eijlant van Poullu ay gepasseert mette geheele vloote, ende t' sauonts voor 't casteel Nassarwo ten ancker gecommen; volghen de naemen van de schepen, jachten, galleije, fregat ende tingans, als voleht:

Admirael.

't schip Hollandia, Nieuv Zeelant. 't jacht 't Hert.

't Waepen van Amsterdam. Zirrickzee. 't Postpeert.

't schip Amsterdam. 't schip Oraingen. den vliegende Bood.

den Dragon, verovert van Schiedam. den Eenhoorn.

d' Engelschen.

den Duijvel van Delft. Enckhü̈sen. de Zeeroolff.

De galleije, 't fregat Arracan, acht en veertich tingans, daer commandeur over was JAN CORNBLIsSEN cunst, schipper op 't schip Schiedam, mitsgaders 't Wapen van Jacquatra, sijnde voor en achter plat, sonder steuen, alleenelijek gemaeckt om op het resiff te brenghen voor Lonthor, om 't selue te beschieten, hebbende vier halue cortouwen ende thien saeckers, rontsom bevrijt voor een basse. 
Gedurende de compste van de Heer Generael is den Raet met den chrichsraet tot diuersche stonden vergaedert ende op alles wel gelet, gereetschap gemaeckt totter saecke dienende, voorts alle de soldaeten, bootsgesellen, Japponnesen, vrije borgers van Jacquatra, Amboinna, Poullu ay ende Neyra, die als doen daer waeren, mitsgaeders de Chiauvers, Mardichers en Gusuratten, al tsaemen in haer volle geweer doen monsteren, op een groot pleijn achter het casteel Nassau; volgen de naemen van de ouericheijt ende cappiteijnen.

De Heer Generael JAN PIETERSz. COEN.

FREDERICK HOUTMAN, Raet van Indiën.

wHLEM vaN ANTSEN, Gouverneur van Banda.

martin 'T' sionck, Fiscael.

THISSEN Secretaris.

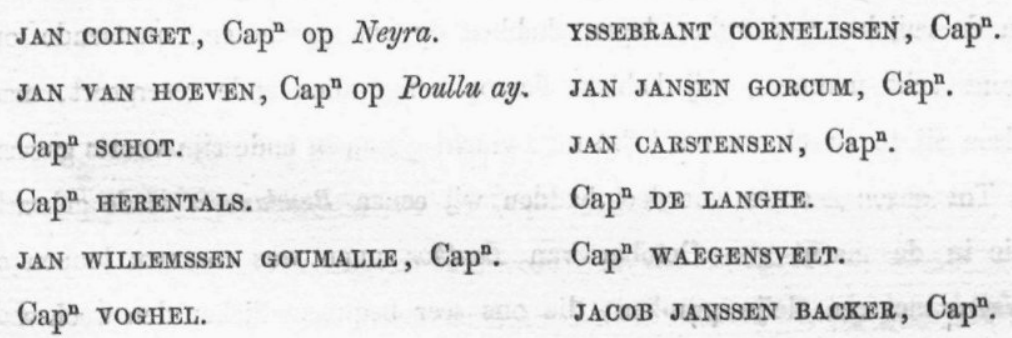

Twee compagnien Japponesen, tsaemen sterck hondert mannen, volcht Chiawwers, Mardickers en d' andere bouen genoemde, wierden altsaemen geestimeert int grosse 10 a 11 hondert mannen ten strijde.

De monsteringhe gepasseert sijnde is ider vertrocken naer sijn quartier, soo 't scheepe als anders.

De 5 Meerte is 't jacht 't Hert gecommandeert geweest achter Lonthor ten ancker gaen liggen voor Lakoij, ophebbende de Compe soldaeten van Cap $^{n}$ JaN van hoEven. Daer voor commende die van Lakoy schooten seer uwt haere vasticheijt, quetsende thien mannen van d' onse, een jongman in de kuijtte het been aff, 'twelk hem afgeset sijnde mede begeerde om op Neyra te begrauen, ende eenen adelborst doot, genaempt MELCHOR SEGERS van Neurenburch. D' onse schooten oock op haer, maer deden weinich schade, doordien haere vasticheijt op de hoochte lach, 'twelk de Heer Generael aen- 
gedient wiert, s' anderdaechs quam de Galleije uwt Banda om ons van 't lant aff te bouchseerden, want wij anders van den wal niet en conden commen. In 't vertrecken wiert den opper-timmerman van Neyra dootgeschooten, genaempt JAN ......., op de reede van Neyra commende wiert de compe soldaeten op 't schip 't Wapen van Amsterdam geforr.....

Den 7 ditto sijn wij vertrocken met de heele macht aen lant ontrent Lonthor, om te besichtigen ofte daer geen bequame plaetse en was om neder te slaen. Geen bequaemheijt vindende, sijn op den middach vertrocken; int vertrecken wiert een Japponees dootgeschooten ende noch drije ofte vier gequest.

Den 10 ditto sijn wij vertrocken achter 't lant tusschen den houck van Lonthor ende Lakoy ende aldaer gelant, ons behelpende met stormladders, de clippen opgeclommen ende alsoo bouen gecommen; $\mathrm{Cap}^{\mathrm{n}}$ corNaET die de voortocht hadde, vergeselschapt met d' Heer houtman, sijn voorts getrocken. Int marcheren vindende een parthije Bandannesen die op de wacht in de ruijchte verborghen lagen, hebben op ons geschoten, quetsende ontrent acht mannen, wij hebben daerop aengevallen ende gesergeert, maer alsoo sij te swack waeren hebben de vlucht genomen ende sijn voorts gegaen.

Tot onsen grooten voordeel hadden wij eenen Bandannees mede gebracht die in de maent van October van Lonthor ouer was commen loopen op Neyra met een cleijn prauken, die ons seer bequaemelijcken den wech wees door 't bosch, ons brenghende van achteren in 't fort van Lonthor op de hoochte daer 't seer weijnich' beurijt was, ende de ingesetenen ons daer niet en waeren verwachtende, sijn alsoo daerinne gecommen sonder eenich rancontre te vinden, alsoo wij neerwaerts waeren commende. Sij ons vernemende sijn sij gevlucht met groote verbaestheit, soo dat wij daervan een deel noch dootschooten ende sloeghen, voorts vonden noch beneden eenighe Chinesen ende Jauaenen die dootgeslaegen wierden, mitsgaeders drije Engelschen, die geuangen wierden ende naer boort gesonden. Int veroueren is schoonen buijt geweest.

Ter seluer thijt was gecommandeert $\mathrm{Cap}^{\mathrm{n}}$ voGEL op $\mathrm{d}^{\prime}$ andere sijde van 't lant aen Orantatte, tegens ouer Neyra, met t' seuentich muskettiers om op de hoochte te climmen, om 't velt t' ontdecken. Int opcommen heeft hij den vijant vernomen, die haer mannelijcken weerden ende tot drijmael toe op d'onse foncheerden, maer mosten int leste de vlucht nemen, alsoo d'onse 
haer soo mannelijcken weerden met een groot courragie dat sij se vluchtich maeckten. Het ginck hiertoe, gelijck de Duijtschen seggen, gelt maeckt moet. Haer lieden was bij d' Heer Generael ider man dertich realen van achten belooft, 'twelk veel doen can, maer 't is te beclaeghen, daer een soldaet om coste ende clederen moet dienen; daer sijnder twee van de parthije doot gebleuen, een corporael met een soldaet, ende eenighe gequeste. Bouen op dehooch te gecommen sijnde, hebben haer in ordre gestelt ende een man om leege gesonden bij $\mathrm{Cap}^{\mathrm{n}}$ GorcuM, die metten troup op strang [strand] haere aduonturre was verwachtende, hem aendienende 't gepasseerde, dat sij oock niet versien en waeren van ammonitie, ouer sulxs strackx soude belieuen voorts naer bouen te willen marcheeren; 'twelk geschiet is. Bouen gecommen sijnde, met blijtschap bij den anderen sijnde, hebben haer in goede ordere gestelt ende alsoo mette beste gelegentheijt naar Lonthor gemarcheert. Het is een schoon ende heerlijck lant, vol schoonder vruchten, maer seer moeijelijck om te marcheeren, doordien het seer berchachtich ende somwijlen boschachtich is, soo dat men een voor een moet gaen; op sommighe plaetsen seer clipachtich. Alsoo sijn wij eijndelijcken op de hoochte voor Lonthor gecommen alwaer sij d' Heer houtman en de Cap ${ }^{n}$ conveEs mette andere parthijen altsaemen hebben gevonden int verouerde fort van Lonthor.

Ondertusschen dat deze twee parthijen besich waeren geweest met landen ende haere tochten te doen, soo was bij d' Heer Generael belast 't schip genaempt 't Waepen van Jacquatra, dat als doen voor Lonthor dicht aant rissiff lach, sonder ophouden op haere vasticheijt souden schieten, mitsgaders het schip Schiedam, dat daeromtrent lach; twelk gedurrichlijck gedaen wiert, om alsoo de Bandannesen te abuseeren ende geen achterdencken te geven dat ons volck op de hoochte souden commen. Ten anderen bleef Cap ${ }^{n}$ GoRcuM beneden opt strang, die sij lieden genouchsaem conden sien staen in ordere, meijnende, hij van daer haerlieden souden commen bestormen, niet verhoet sijnde op de troupe van $\mathrm{Cap}^{\mathrm{n}}$ coINGET ende de parthije van $\mathrm{Cap}^{\mathrm{n}}$ voGeL die haerlieden de doot deden, soo dat sijlieden daerdoor geheel in confusie sijn gecommen. De vasticheijt van Lonthor is gelegen tegen ouer de gounapij ${ }^{1}$, twelck eenen seer hooghen ende breeden berch is, die gedurich-

1 كونغ أفى Goenong api, Vuurberg.

Downloaded from Brill.com04/26/2023 05:22:12AM via free access 
lijek dach ende nacht brant ende grooten damp van hem geeft. Heeft eertijts vol schoone vruchten gestaen van nooten ende follie, maer als hij ouer seuen jaeren met grooter cracht heeft gespronghen, sijn alle de vruchten bedoruen, ende de inwoonders gevlucht. Is int ronde ontrent twee millen, liggende rontsom int waeter, soo dat tusschen de Gounapy ende Lonthor de rechte incompste is van de schepen om voor Neyra ende 't casteel Nassau te anckeren. De vasticheijt van Lonthor is een seer stercke plaetse, bestaende in drije forten bouen den anderen, voor eerst beneden opt strang onder de voet vant geberchte, een steenen muragie hoogh ende dick, seer propijs gemaeckt, met haere punten ende gordijnen, flanckeerende op malcanderen, wel versien van schut, te weten vier gotelijnghen die sij van d' Engelschen hadden gecregen, voorts valcoenen ende bassen; het tweede licht seer halff wegen 't geberchte, twelcke niet dan clip ende steenrotse en is, nochtans seer sterck bemuert; het derde licht seer bij op de hoochte, seer vast bemuert ende voorsien van bassen. Bouen op een clip ter sijden naer 't water lach noch een gotelijnck, ende voorder, naer de sijde van Neyra, noch twee gotelinghen, die in battarie seer wel gestelt waeren tot haer lieder voordeel. Voorder wasser bouen op de hoochte van 't geberchte eenen langen muer, seer hooch, streckende naer de sijde van Sallamme, met punten seer wel versien; maer aen dander sijde van Lackoy en was geen sterckte, maer seer hooghe bergen, soo dat se ons van daer niet en waeren verwachtende. Sij waeren oock seer wel voorsien van seer cloekmoedich volck, hadden oock groote menichte van musketten, langhe roers, cruijt, loot ende lonte, veele met schilden ende sweerden, daer sijlieden seer wel weeten mede om te gaen, voorder met blinckende stormhoeden op haere hoofden, soo blanck als silver, twelck een lust omm sien was; waeren oock wel geresolveert te vechten, soo dat dese vasticheijt van Lonthor, haeren eenighen troost was, vant geheele lant; maer alsoo sij haer van bouen saeghen bespronghen, niet wetende van haere parthije die in de, vlucht geslaeghen was, int aencommen van d'onse op de hoochte; ende aen den watercant geen uwtcomste en saeghen, oock onmoghelijek was haer te stellen tegens d'onse die op de hoochte alreets waeren, want één man bouen wasser twointich beneden machtich, alsoo haere sterckte teghens de hoochten oppen waeren; soo sijn sij heel desperaet gevlucht, als bouen verhaelt. 
Den elfsten Meerte is bij d' Heer Gouverneur ende die van sijnnen Raede gecommandeert seckere trouppen naer Samber ende Lackoy omme deselue vasticheden inne te nemen. Samber is, naer menschelijcke wijse te sprecken, een onverwinnelijcke plaetse. Is gelegen aen de zeecant op een hooghen berch, seer steijl ende elipachtich, rontsom met hoogen bergen omringt met seer diepe valleijen, soo dat een schrick is onm legge te sien. Het heeft twee inganghen, seer smal, soo dat een mensch een hant ofte voet failieert apparent is doot te vallen. Men moet eerst van de hoochte om leege gaen ende dan weder op naer de hoochte climmen, een man teffens, soo dat een man binnen sijnde, jae hondert van buijten met steenen can dooden ende wederstaen. Niet tegenstaende alle perijckel onse trouppen daer commende, naer seeckere schermutsinghe van loosen allarm en de schieten, hebben die van binnen door de voorighe verbaestheijt van 't verlies van Lonthor de vlucht genomen, ende alsoo sijn d' onse binnen gecommen, vangende noch eenen Bandannees, laettende aldaer tot verseckeringhe den $\mathrm{Cap}^{\mathrm{n}}$ HERENTHaLs met sijnne comp $\mathrm{p}^{\mathrm{s}}$, vindende daer seckere valcoenen ende bassen, met parthije sagouw, waeterpotten, porceleijnen ende huisraet.

Voorts commende op Lackoy, twelk een goede vasticheit was, rontsom bemuert, hebbende twee vaste besloten poorten, d'eene aen den waetercant, d'ander aen de lantsijde op de hoochte, hebben 't selve ledich geuonden. Daer waeren eenighe bassen, een iseren goetelinck ende andere waeren van cooperwerck, porceleijn ende anders, dat de gevluchte niet en hadden connen berghen. Alsoo sijn deese arme menschen gevlucht met wijff ende kinderen in groote verbaestheijt, vergeetende haere voorighe cloeckmoedicheijt, in de hooghe berghen, alsoo ghij noch verstaen sult.

Onse trouppen haere commissiën volbracht hebbende, hebben ten deele het bosch gepasseert, om haeren vijant te crencken ende vluchtich te maecken, ende sijn alsoo op Lonthor gecommen sonder eenighe schade.

Voorder is bij d' Heer Generael belast dat elck soude vertrecken naer sijn garnisoen ende schipsboort, latende op Lonthor drije compagniën soldaeten. Int veroueren van dese plaetsen isser een grooter menichte van nooten ende foellie gevonden ende op Neyra gebracht, 't sal de costen helpen betaelen soo de waeghen recht gaet.

Die van Sallamme, Waeijer ende Demmer, die haer in haere vasticheden 
stille hadden gehouden omme te sien met wie de canse draeijen soude, verstaen hebbende den onderganck van die van Lonthor, Samber, Lackoy ende Orentat$t e$, 't verlies van haere forten, volck ende goet, 't welck haer te vooren eene onmooghelijcke saecke dochte te wesen, soo sijn sij met een corte resolutie gecommen met een vreede vlagghe bij d' Heer Generael, mede brenghende een gouden keeten met een cooperen becken, een nootenboomken met eerde ende meer andere vruchten ende bocken, ootmoet versoeckende, met seckere artickelen bij haerlieden gemaeekt ende ouergegeven, presenteerende voor eerst 't lant mette vruchten to transporteeren aen den Prins van Oraingen in Hollant ende hem te erkennen als Souvereijn Heere ende geenen anderen.

Volghen d' artickelen bij haerlieden ouergegeven als volcht:

1. Om te moghen blijuen in haer besit ende vrijicheijt haeres geloofs.

2. Dat niemant eenich gewelt aen haere vrouwen ofte kinderen en soude begaen.

3. Dat niemant in haere huijsen en comme om quaet.

4. Dat men niemant 't sijnne ontroue tegens sijnen danck.

5. Dat men niemant van de haere sonder rechtelijcke rede en soude slaen.

6. Dat men niemant van de haere tot eenich werck niet en soude gebruijcken, alsoo sij sulcken werck niet gewent en waeren te doen.

7. Dat se beriet waeren, soo 't den noot verhiesch, daer 'eenighe vijanden quaemen, ten dienst van den Prins van Oraingen souden staen, maer niet geëmploijeert en souden worden buijten s' lants te gaen vechten.

8. Dat men den Bandannesen die van haer tot ons souden commen loopen weder souden ouerleueren, gelijck sijlieden weder aen ons sullen ouerleveren de Nederlanders die bij haer souden commen loopen.

Volghen d' artickelen diè sijluijden ons belooft hebben als volcht:

1. Dat sij altsaemen sullen sweeren ende bekennen de Ed. Mog. Heeren Staeten ende sijnne princelijcke Exell. voor haer ende haerder naecommelinghen hooft ende Heeren, belouende deselue in aller getrouwicheijt (sonder eenighe listicheit) te dienen, als oock mede aen den Gouverneur die van den Generael hier in sijnne plaetse gelaeten sal worden, ofte oock die hier bij den Gouverneur in sijnne plaetse gestelt soude moghen worden. 
2. Dat se haer lant mette casteelen ende vruchten geuen in handen van den Generael, gelijck sij ook bij deesen waerelijcken (sonder eenigh bedroch) in sijnne handen geuen, sonder dat iemant anders daarop iets sal hebben te pretendeeren, bekennende hiermede de Ed. Mog. Heeren Staeten ende sijnne Prinselijcke Exell., ende geene anderen voor haere hooft ende wettelijcke Heeren.

3. Tot een erkentenisse van dien sullen sij haeren heere betaelen de thienden van alle haere vruchten.

4. Sullen haere vruchten nergens te coop brenghen als op Neyra ende Poulluay aen de cooplieden aldaer; sullen oock leuerbaer goet moeten leueren.

5. Sullen oock geen sterckten moghen maecken, maer sullen gehouden wesen beneden op 't strang te commen wonen.

6. Indien den Gouverneur van Banda eenighe hulpe van doene heeft, tsij in oorloghe off int maecken van sterckten, sullen hem (soo veele mogelijcke) terstont helpen, doch dat volgens de belofte haer gedaen.

7. Sij en sullen selue geen recht moghen doen, maer alsser iet voorvalt snllent den Gouverneur aendienen, dewelcke dan mette Orangcaijs ${ }^{1}$ van 't lant de saecke sal affdoen.

8. Soo belouen ende sweeren sij, haer te houden tegens haeren heere, gelijck cen goede ende oprechte gemeijnte betaemt, ende sonder eenighe list naer te commen alle de ordonnantiën ende geboden die hij hen geuen soude.

9. Dit alles sweeren sij luijden niet alleen voor haer seluen, maer voor alle de geene die op haer lant sullen commen wonen, belouende ook te helpen dattet van andere naergecommen soude worden, ende te helpen straffen, die daer tegens sullen commen te doen.

Dit accort is beswooren bij alle de Orangeaijs bouen verhaelt, ende sijn alsoo van den anderen gescheijden.

Daer is bij d' Heer Generael ende den raet op Lonthor, op de hoochte op den houck naer de sijde van Sallamme, een fort afgesteecken met vier punten, liggende seer bequaem soo te waeter als te lande, ende daedelij-

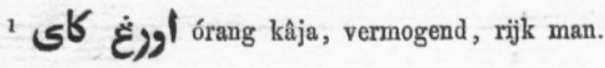


cken in 't werck gestelt. De bootsgesellen van schepen mostender aen wercken, soldaeten, ende een groote parthije geuangenen Jauannen twee ende twee, aen een langen ketten, die den Generael medegebracht hadde van Jacquatra, Jappara, Bantam ende andere.

D' Heer Generael heeft voorder alle deligentie gethoont ende is met twintich tingans, slouppe, boots, corre-corren, met alle de resterende soldaeten van Neyra naer Poulluay gecommen ende hebben daer vernacht.

Tsanderen daechs sijn de tingans met de slouppe, mette geheele macht vertrocken naer Poulluron om 't selue te bestormen ende de Bandannesen uwt te roeijen, daer alsdoen op ancker was liggende de Engelsche Stiere.

De inwoonders van 't lant onse vloote siende aencommen, tot omtrent haer strant, hebben tot diuersche plaetsen vreedevlaggen opgestocken, alsoo dat ons volck wederomme aff is gekeert, ende eenighe van de ouerste sijn aen de Stiere geuaeren, ende naer den middach aen Poulluron aen lant geuaeren, te weten, den fiscael MARTiN 'T' sronck, Mr. HaYs Engelsch coopman ende JASPER STEVENSSEN voorleser, als tolck. Ondertusschen is 't jacht ' $t$ Hert aldaer op de reede gecommen, settende neffens de Stiere. Ons volck gelant sijnde sijn bouen geclommen; siende van lant afuaeren twee vis prauwen, alsoo is onse vloote wederomme gekeert ende op den achtermiddach op Poulluay gearrineert.

Den fiscael T' sIovck bouen gecommen sijnde, is haerlieden te gemoete gecommen, den ouersten Orangcay met de sijnne, die haer geleijt heeft tot onder haere stadt, dewelcke wel bemuert was, ende met haer int lange gesprocken hebbende sijn van daer vertrocken, ende weder naar de Stiere geuaeren, ende op den auont laet op Poulluay gecommen, hebben d' Heer Generael 't gepasseerde gerapporteerd.

Den tweeden dach daernaer sijn die van Poulluron op Poulluay gecommen met twee Orangbays ${ }^{1}$, mette paep opperste Orangcay van 't lant ende meer andere, versouckende ootmoet aen den Heer Generael, met haer lieden brengende een schootel met eerde met een nootenboomken, bocken, clappessen, benannessen, pinnan $^{2}$ ende andere vruchten van den lande, presentee-

${ }^{1}$ (ب), Orembaai, Statie vaartuig. (Molukken)

${ }^{2}$ نئن Pinang, de Areka- of Betelnoot. 
rende alsoo het lant ende vruchten in handen van den Generael; alsoo sij $\mathrm{nu}$ in 't langhe met de Heer Generael ende den raet hadden gesprocken sijn sij wederomme naer Poulluron vertrocken, omme met de gantsche menichte te sprecken ende haerlieden d' artickelen voor te houden die haer bij den Generael waeren voor gelecht, volghens die van Sallamme, Waeijer ende Demmer.

Het is grootelijkx te verwonderen ende gaet alle verstant te buijten, dat dese menschen die soo vast waeren geseten, in seer corten tijd haere landen abandonneerden; want Poulluron is een hooch clipachtich lant, wat grooter als Poulluay, maer niet soo vruchtbaer, is een seer sterck eijlant, d' opcomste seer priculeus, soo dat sij bij touwen van rottang gemaeckt opclimmen om in haer vasticheijt te commen, ja is soo te seggen naer menschelijcker wijse onwinbaer, licht rontom int waeter, het heeft een cleijn eijlandeken aen den houck van Poulluay, daer de Engelschen een fort op hebben, ende met leegh waeter connen sij bij den anderen commen, op 't eijlandeken en is geen geboomte noch eenige vruchten.

D' Heer Generael heeft alle saecken op Poulluay in goede ordere gestelt, soo van fortificatie, als negotie, voorder aengaende 't republijcke soo van vrij luijden als van onvrije, oock 't verlossen van de soldaeten die haeren tijt geëxpireert was, als oock in 't vermaeken van officieren, nemende sijn afschiet van Poulluay, is weder vertrocken mette geheele macht naer Neyra, houdende sijnne residentie op 't schip Hollandia, Admirael van de vloote.

Aldaer gecommen sijnde is bij d'Heer Generael ende die van sijnnen raede, den fiscael MARTIN T' sIoncK Gouverneur gemaeckt ouer d' ejjlanden van Banda, in de plaetse van WILLEM vaN ANTSEN, die door sijnne swacklijuicheijt de plaetse niet bequaemelijek en conde bedienen, ten anderen de forten aldaer seer quallijck versien sijn van Spaenschen wijn, is ditto vAN ANTSEN Raet van Indiën gemaeckt om sijnne residentie op Jacquatra te houden. Ter seluer tijd is vrijborger geworden $\mathrm{Cap}^{\mathrm{n}}$ JAN vaN HOEVEN, die naer 't veroueren van 't eijlant ende fort Poulluay als Cap" aldaer in Guarnisoen geleijt wiert; heb hem als doen gekent geen thien realen van achten in contant en hadde; wiert bij den Generael LAURENs REAEL opt vertreck van Luitenant Gouverneur ADRIAEN VAN DER DUSSEN in sijnne plaetse gestelt, totte compste van eenen anderen; is in dien corten tijd soo 
geprospereert, Godt loff, dat op ons vertreck om gheen acht ofte thien duijsent realen sijn goet ende contant en soude missen. Heeft op eenen thijt vier duijsent aen de comptoiren gedaen; ' $t$ is heuchelijck.

Die van Poulluron met haere geheele gemeente beraetslaecht hebbende, hebben geconsidreert 't verlies van Lonthor ende d' andere plaetsen; siende ter andere sijden den vrede die daer gemaeckt was met die van Sallamme, ende voorder geen wtcompste siende, soo dat haere voorgaende mannelijcke couraighe nu geheel geflauweert was, soo sijn sij eijndelijeken gecommen met een volcommen resolutie bij d' Heer Generael op 't schip Hollandia, in tegenwoordigheijt van den geheelen raet, ende hebben eenen vasten onuerbreckelijcken peijs gemaeckt voor eeuwich, op de selfde artickelen als die van Sallamme, Waeijer, Demmer, ende Comber gesloten, als hier voren gespecificeert staen.

De verloste Guarnisoenen, die haeren tijt geëxpireert waeren, sijn gelicht, soo van Neyra als Poulluay, ende wierden geordonneert op 't schip Hollandia, waeren tsaemen hondert en ses personen, die van Poulluay wierden gelicht op den $2^{\text {den }}$ en $4^{\text {den }}$ April anno 1621.

De fortificatie van het nieuw begonnen fort op Lonthor wiert seer gevordert ende was ten deele in defentie tegens eenen aenloop. d' Heer Generael vermoedende dat de gevluchte Bandannesen, die op de hoochte ende elders haer onthielden wederom versaemelen mochten, ende op ons onverhoetste, ons commen bespringhen, ten anderen haerlieder ten deele mochte gelucken, lichtelijck d' andere die in vrede met ons getreden waeren, haer souden toegevallen hebben, alsoo de swarten niet te betrouwen en sijn, wiert geordonneert, dat alle de verloste soldaeten, voorts een deel bootsgesellen die noch op de schepen waeren, op Lonthor mosten commen ende aldaer alle de huijsen afbrecken, ende 't hout van dien te brenghen aen 't fort, waervan rontsom het fort een stercke pallassada gemaeckt wiert tot haer lieder verseckeringhe; daer waeren guarnisoenen genouch om dit perijekel te verseckeren, die tocht nochte wacht en deden; ick meene dat de huijsen nu noch stonden, haer lieden beter te nutte souden commen als de pallasada, maer somwijllen vint men in raeden eenighe persoonen die $s^{\prime}$ nachts meer weien als daechs ende dat moet dan voortgaen, val wel, luck wel.

Den twintigsten April is d' Heer Gouverneur MaRTEN T'sIoncK door last 
van den Heer Generael met een deel tingans, schuijts ende boots, met vijff Compagnien soldaeten naer Sallamme gevaeren, die als noch met ons in vrede waeren, haer liede aendienende dat onse passagie aldaer ons was dienende tot verstroijinghe van de gevluchte Bandannesen, grootelijck dienende tot haer lieder voordeel. Boven op de hoochte, dewelcke seer steijl is, gecommen sijnde, sijn wij in ordere gestelt ende de passagien beset met muskettiers, duerende totten middach; de Bandannesen meijnden dat wij door gepasseert souden hebben, maer 't geschiede geheel tegens haer geuoelen. d'Heer Gouverneur met den raet vergaedert sijnde, heeft bij hem ontbooden den Orangcaij JARREN, ouerste van Sallamme met de andere, haer lieden vooren houdende ofte sij geenen middel en wisten omme de gevluchte Bandannesen van Lonthor, Laccoij ende Samber, die met vrouwen ende kinderen ende slauen op eenen seer hooghen grooten berch gevlucht waeren; daer aff te moghen crijghen; gauen voor antwoorde, haerlieder debuoir daerinne te doen, ten dienste van den Heer Generael.

Voorder heeft d'Heer Gouverneur d' Orangcaijs voorgehouden als dat sij de Compe versien mosten van huijsvestinghe, alsoo hij seijde van meeninghe was daer eenighe daeghen te blijuen, 'twelck haer lieden niet wel en behaechden. Den Gouverneur heeft voor eerst begeert den tempel die bij de balleije ${ }^{1}$ stont, daer hij metten raet ende een Compe soldaeten opgeforriert was, 'twelck sijlieden weijgerden, maer seijden andere huijsen daertoe gereet souden maecken, die bequaem souden wesen; gaff voor antwoorde als dat hij den tempel daertoe gebruijcken woude, alsoo daer geene bequaemer plaetse en was tot sijnner verseckeringhe, ten anderen, volghende 't bespreck, den tempel ende alle de huijsen af mosten (brecken) ende in de leechte aen 't strant gestelt mosten worden. Den tempel was een schoon gesticht naer haere wijse, hij was wel veertich voeten viercant, bemuert met witten gehouwen steen, seer net gewrocht, hebbende eenen inganck, met trappen opgaende; van binnen was hij luchtich gelijck een borstweeringhe, soo dat een man daer in gaende, tusschen den muer ende 'thoutwerck van de cappe bequaemelijcken door sien conde. De cappe was van seer schoon hout gemaeckt ende nettelijck gewrocht, drije hooch bouen den anderen, viercant,

1 م بالى balie-balie, openvertrek voor raadsvergaderingen. 
volghende den muer, voorts bouen open met een ront gat; hij was gemaeckt dat men van binnen seer bequaemelijcken te waeter ende te lande conde uwt sien, hadde van buijten oock rontomme eenen breeden pat van witten steen gehouden, daer men bequaemelijcken drije persoonen neffens den anderen conde wandelen; voor de deurre aen den tweeden trap stonden twee groote waeterpotten, vol waeter, daer sijlieden haere voeten wassen ende reijnighen eer sijlieden in den tempel gaen, van binnen en is geen chiraet als eenen grooten stoel, tegens ouer de incompste; de vloer met matkens bedeckt, om haere voeten niet te ontreijnen, voorts een coopere lampe met veele lemmetten brandende.

d'Heer Gouverneur desen tempel aldus begeert hebbende waeren sij bedrouft, ende ommekeerende hebbende sij met malcanderen gesprocken ende sijn wedergecomen tot den Gouverneur, versouckende, dat sij haer lieder sabat daer noch eens inne mochten houden, 't welck noch twee daeghen soude aen geloopen hebben. Gaft haer voor antwoorde, sij noch meer tempels hadden, ende heeft alsoo daedelijeken de Comp van Cap ${ }^{\mathrm{n}}$ VAN HOEVEN ende $\mathrm{Cap}^{\mathrm{n}}$ schот gecommandeert daerinne te trecken. Sij dit siende hebben haer afschiet genommen ende sijn seer bedrouft naer haere huijsen gegaen. De resteerende Compe wierden in de bequaemste huijsen geforriert; daer wierden desen nacht seer veele schiltwachten uwt gestelt ende seer neerstelijck de ronde gegaen, soo dat wij altsaemen dien nacht meest in roere waeren. Des anderen daechs vrouch is d'Heer Gouverneur metten raet vergaedert; d'Orangcaijs ontboden hebbende sijn gecommen; haerliede vraeghende ofte sij de saecke hier voor verhaelt, van meeninghe waeren bij de hant te nemen, seijden Jae. Alsoo sij nu tsamen int lange met malcanderen hadden beraetslaecht, ende de Gouverneur haer lieder instructie hadde gegeven om de gevluchte te bejegenen met schoonne beloften, sijn vertrocken ende nae de hoochte gegaen. Met haer liede gesprocken hebbende, sijn wedergecommen, in alle neersticheijt medebrengende den Oversten SEBANDER ${ }^{1}$ van Lonthor ende eenige slauen. Dit geduerde den geheelen dach. Sij bewesen groote neersticheijt, 't welck den Gouverneur ende raet wel behaechde, den Sebander vereerde den Gouverneur eenen gouden crits, de Bandannesen die

1 Sjah-bandar, havenmeester. 
sijluijden aff gebracht hadden, wierden naer boort gesonden aan den Dragon, sijn weder vertrocken naer haere hüjsen, belonende noch meerder perthije te brenghen. Die van Salamme mette anderen siende onse guarnisoenen als nu op de hoochte van haer lant, ende dat sij vermeestert waeren, ten anderen, haeren tempel daer sij seer veele van waeren houdende, oock haere huijsen die haer ontrocken wierden, vreesende als dan int leste haer lieden mockte gelden, soo hebben sij een pratijcke gevonden, meijnnende ons al tsaemen te slaen bij nachte, 't welck oock sonder twijfel soude geschiet hebben, ten waere de goede Godt ons merckelijck niet en hadde bewaert, want in plaetse van die, die op de hoochte waeren te vermurwen tot vreede ende aff te commen, hebben ter contrarien tsaemen een verbont gemaeckt.

Die van Sallamme, onder schijn van getrouwicheijt, versochten aan d' Heer Gouverneur om beneffens d'onse de wacht te honden tegens die op de hoochte waeren, seggende sij lieden haer niet en betrouden, wiert haer geconsenteert op haere quartieren te mogen doen, sonder omtrent onse uwt gestelde wachten te commen.

Op de voorgaende belofte van meerder perthije aan te brenghen, soo hebben sij van bouen op den achtermiddach een heel deel vrouwspersoonen beneden gesonden, vergeselschapt metten grooten Sebander van Lonthor ende Orangeaij Jarren Overste van Sallamme ende d' andere, commende seer cierlijeken gecleet, eenighe met gouden kettenen, ende costelijcke behangen, met bedeckten aengesichte om ootmoet te versoucken aen den Heer Generael, voor haer, haerlieder mannen, kinderen ende slauen, onder belofte, als dat haere mannen ende alles wat bouen was afcommen souden, haerliede geheelijcken ouergevende tot sijnnen goeden wille; commende voor d'Heer Gouverneur metten raet, die haere compste waeren verwachtende, soo hebben sij eenen voetval gedaen ende haer versouck is bij den Orangcaij Jarren verthoont, waer op d'Heer Gouverneur haerliede dede opstaen, seggende sij wél gecommen waeren, gaff ten antwoorde alsoo d'Heer Generael t' scheep was in de vloote, hem daervan souden adviseeren; den Orangcaij Jarren haerlieden 't selue aendienende, gauen voor antwoorde, het goet was, presenteerende tot breeder verseekeringhe al tsamen dien nacht daer te blijuen, verwachtende beschiet; 'twelck geconsenteert sijnde, is haerlieden een huijs geordinneert daer sij altsaemen ingingen, 't welck met schiltwaëhten 
beset wiert, opdat haer geen ouerlast van iemand en soude geschieden, soo is ieder weder vertrocken in sijn quartier, die geduerende dit verthooch alt. saemen in de waepenen hadden gestaen.

d' Heer Gouverneur heeft daedelijcken d' Heer Generael hier van geadviseert, sendende een tingan naer 't schip Hollandia. De missiue gelesen hebbende sijn tsaemen daerouer verblijt geweest, meijnnende dit alles ter goeder trouwen geschieden, naerdemael de vrouwen met sulcken vrijwillinghe in bewaeringhe waeren.

Terwijllen dese vrouwen bij ons waeren hebben die van Sallamme dien nacht, als bouen versocht, goede wacht gehouden, rouppende naer haere wijse deurgaens van bouen naer beneden ende weder voorts Sagge, Sagge...1, om ons te abuseeren, opdat sij haer exploot te beter mochten voorderen.

Een volcommen resolutie van de Bandannesen, die tsaemen meijnden dien nacht haer exploot te executeeren ende int werck te stellen, ende alsoo donse te verasschen ende te slaen, daertoe die gevluchte van de hoochte in haer volle geweer tot omleege gecommen waeren, seer nae bij 't huijs van den Orangcaij JARREN, wesende niet verre van onse schiltwacht, daeruan wij de kennisse daernaer hebben gecreghen bij haerlieder eijgenne confessie, alsoo ghij noch verstaen sult.

Soo ist gebeurt door de goede voorsienicheijt Godts om haer boos voornemen ende mordadicheijt te beletten, datter ontrent den middernacht een lampe hanghende in de balleije daer de Heer Gouverneur met die van sijnnen raede laeghen en sliepen, van bouen neder gevallen is, waerdoor soo groote beroertc ende oploop gecommen is, dat het heele quartier in allarm stont, met sulcken verbaestheijt, datter eenighe van d' onse malcanderen quésten, want het was heel duijster; de uwtgesette schiltwachten die niet vernomen en hebben, bleuen staen met groote verwonderinghe; de ronden sijn seer neerstelijcken omgegaen, de schiltwachten vraeghende ofte sij niet vernomen en hadden, antwoorden neen, voorts haer belastende wel toe te sien, ende soo sij iets vernaemen allarm maecken souden ende afcommen totte tweede schiltwacht. Ondertusschen heeft d' Heer Gouverneur mette Cappiteijnen ende andere officieren, 't geheel quartier wel besichticht. De

1. جأَ djaga-djaga, oppassen; pas op! 
beroerte gestilt sijnde, hebben bevonden 't vallen van de lampe d' eenighe oorsaecke was. Daer wierd door last seer dapperlijek geschooten met musquetten uwt ons quartier om den vijant verbaest te maeken. Geduerende desen allarm sijn de voorschreuen vrouwen, die in bewaeringhe gecommen waeren om ons t' abuseeren, gevlucht, alsoo haerlieden de passagiën beter bekent waeren als d' onse, oock op haere hoede stonden; door den seer donckeren nacht te beter bequaemheijt hadden, vluchtende niet beter en wisten ofte beijde parthijen waeren aen malcanderen, ende sijn alsoo bij de haere gecommen. Wij sijn altsaemen in volle waepenen blijuen staen, in goede ordere, uwtstellende scherpe wachten, dicht rontsom ons quartier, laettende ommegaen ronde op ronde, doch aenmerckt de groote suptilheijt van dese Bandannesen ende haere cloeckheijt, siende haeren aenslach ontdeckt ende niet uwtrechten en conden, ende om alle suspitie te weeren, hebben de vrijmoedicheijt genomen ende in ons quartier gesonden, hoorende alles in stilheijt was, den Orangcaij JARREN, die gecommen is tot aen onse uwtgesette schiltwacht met brandende dammers ${ }^{1}$ op haere wijse, seer licht brandende. De schiltwacht gerouppen hebbende, heeft versocht d' Heer Gouverneur te sprecken; 't rapport gedaen sijnde, is geconsenteert hem in te laeten commen, met die, die de dammers droughen; bij d' Heer Gouverneur gecommen sijnde, geliet hem seer verbaest ende verslaeghen, naer dat hij rèurentie gedaen hadde, heeft hij gevraecht, wat d' oorsaeke was geweest van die groote beroerte ende allarm, seggende dat sij altsaemen daer ouer seer verschrickt waeren, dat alle de mans, vrouwen ende kinderen gevlucht waeren int bosch, vreesende men sou dese altsaemen commen vermoorden, voorts groote moeite soude hebben om haerliede weder te doen commen ende den schrick uwtten hoofde te stellen. D' Heer Gouverneur gaff voor antwoorde, als dat hij hem ende alle d'andere, vrienden sijnde van den Heer Generael, van ons verseckeren soude, haerliede geen quaet en soude geschien, maer ter contrarien alle hulpe ende bijstant, ende 't geene gepasseert was int maecken van den allarm een abuijs was, hem recommanderende sijn volck ' $t$ selue aen te dienen ende wederomme in haere huijsen te doen commen, 't welk hij beloofde te doen. Dese belofte was licht te

${ }^{3}$ folo damar, fakkel van harst. 
volbrenghen, want sij en waeren niet verre. Aldus heeft hij oorloff genomen, bewijsende groote eerbiedinghe aen d' Heer Gouverneur ende raeden. Int passeeren van alle de soldaeten die in haer volle geweer in ordere stonden thoonde hij een blij gelaet, ende is alsoo bij de sijnne gekeert. Hier vooren heb ik verhaelt, hoe die van Sallamme wacht waeren houdende ende totten anderen waeren rouppende, maer de canse gemist sijnde, men en heeft haeren haen niet meer hooren craeijen.

D' Heer Generael op de reede liggende voor Neyra, door 't gehoor van 't schieten 't welck in ons quartier gedaen wiert, is daer ouer seer verwondert geweest, alsoo hij 't seer bequaemelijcken conde hooren door den duijsteren nacht; daer wierden groote.... gegeuen, maer ten duerde niet langhe, daerdoor d' Heer Generael presumeerden, de Bandannesen op ons eenen aenval mosten gedaen hebben, ende alsoo 't schieten ophielt, daer uwt oordeelden d' eene parthije ofte d' anderen schaede moste geleden hebben, heeft derhaluen daedelijek order gegeuen omme d' andere compagniën te lichten, soo soldaeten als bootsgesellen, 't welck in dien seluen nacht al gevoordert is, ende sijn smorgens vrouch met noch vier comp ${ }^{n}$ bouen op de hoochte van Sallamme gecommen, ende elck sijn quartier gegeuen. De compagnie van $\mathrm{Cap}^{\mathrm{n}}$ coINGET is gecommandeert om leeghe te trecken aen strang, omme de tingans, boots ende schuijten te bevrijden, alwaer die van Sallamme ten deele haere huijsen hadden begonnen te maecken volghende 't bespreck. Voorder is d' Heer Generael van den allarm geadviseert.

Den Orangcaij JARREN met den Sebander van Lonthor met meer anderen sijn bij d' Heer Gouv ${ }^{r}$ gecommen, alsoo sij seijden gehoort te hebben dat d' Heer Generael haerliede, mitsgaders joncker DIRRICK CALLENBACKER ende de paeppe van Waeijer, principaelste Orangcaijs van den lande, binnen sijn schipsboort mondelinghe woude sprecken, bereijt waeren te doen, daerouer sijlieden d' Heer Gouverneur baeden haerlieden daertoe behulpich te willen wesen; alsoo isser gereetschap gemaeckt, ende sijn aen boort geuaeren. Niettegenstaende alle goetwillicheijt van de Bandannesen, soo en heeft d' Heer Gouverneur haerlieden niet betrout; hij heeft onder't beleijt van den Luijtenant CRAENEVELTT een parthije van dertich musquettiers naer bouen gesonden op de hoochte, 't welk wel anderhalff urre gaens was bouen de hoochte van Sallamme. Bouen aen haere vasticheijt gecommen sijnde, hebben die 
van binnen geschooten, quetsende twee soldaeten, ende den Luitenant voorts gaende, wiert met een spiese door den arm gestecken ende sijnnen jonghen wiert met een sagge sagge ${ }^{1}$ in den buijck leelijeken gequest ende noch een soldaet in den voet gequest, ende alsoo sij door de engichheijt van den pat maer een teffens en conden gaan, geen voordeel siende, ten anderen van binnen seer sterck waeren ende groot getier maeckende; sijn sij afgetrocken, ende beneden gecommen, d' Heer Gouverneur 't schieten gehoort hebbende op de hoochte, heeft NICLAES GURRY, Luijtenant van Cap ${ }^{\mathrm{n}}$ corNGET met noch een parthije naer bouen gesonden, die malcanderen int afcommen hebben ontmoet ende sijn alsoo tsaemen int quartier gecommen, de gequeste wierden vermaeckt.

Daer was bij d' Heer Generael op Waeijer ende Demmer een ondercoopman geordonneert, genaempt JAN DE BIE van Middelborch, met eenen assistent ..... sEYs ende eenen jonghen, om aldaer toe te sien dat de Bandannesen haere vasticheden afbrecken souden, volghende 't bespreck, daer van hij als nu ende alsdan naer gelegentheijt d' Heer Generael quam verwittighen.

Dese voornoemde Orangeaijs te weten den Sebander, joncker DIRRICK CALLENBACKER ende den paep van Waeijer aen boort gecommen sijnde, sijn verhoort bij d' Heer Generael, haerlieden voorhoudende, haere groote hoouerdije ende moetwillicheijt, die sijlieden nu den thijt van vijffthien jaeren tegens den Prince van Hollant ende sijnne ondersaeten hadden begaen, niettegenstaende sij haerlieden niets dan alle redelijckheijt ende billicheijt hadden vooren gelecht, om met haerliede te handelen, 't sij met contanten, cleedinghe ofte rijs, naer haer beliefte, tegens haere vruchten, te weten nooten ende foellije, tot eenen seckeren pris, ouer wedersijden geaccordeert; ten anderen, alle verbonden ende contrackten van vrede gemaeckt, bij haerlieden eerst door eenen quaeden iuer waeren gebroocken, voorder oorsaecke waeren van veel vergootten bloets ouer wedersijden; oock haerliede noch wel indachtich was de leelijcke moort van den Admirael PIETER wILLEMSSEN VERHOEVEN, met alle die bij' hem waeren, gecommen sijnde om met haerliede in aller getrouwicheijt te handelen ende sprecken, doende op haer

1 Mogelijk Sagâ سُّ, een soort van riet. 
lieder begeerte sijnne soldaeten van hem aftrecken naer het fort, ende daernae soo meneedelijcken sijn gecommen vermoordende alles wat daer was, met haer volck die sij soo schelmachtich in de ruijchte hadden gelecht; voorts alle vreede handelinghe met haer nae dattum gemaeckt nooijt oprechtelijcken en waeren gehouden, dat oock d' Heer Generael LAURENS REAEL omtrent vier jaeren voor desen, met sijnne vloote ende leger alhier sijnde, haerliede den vreede heeft gepresenteert, 't selve geweijgert hebben, is daerdoor veroorsaeckt geweest hem te begeuen op de hoochte van haer lant, onder haere vasticheijt, meijnende sij daerdoor beweecht soude worden haer te verootmoedighen tot vreede, maer hebben seer wreedelijeken op d' onse geschooten, eenighe doot ende (een) deel gequest, hoewel haer, nochte haere huijsen, nochte haue iets beschaedicht en wiert.

Door alle dese $\overline{\mathrm{en}}$ meer andere redenen van groote mordadicheijt ende moetwille, niettegenstaende het eijgendom van de lande haer niet en was toecommende maer den Coninck van Ternaetten, als wesende d' eijlanden van de Molluckes, die deselue hadden in vrijen eijgendom gegeven aen den Prince van Hollant, mits conditie, hij deselue door sijnnen gecommitteerden metten sweerde soude winnen ende sijnne gerebelleerden ondersaeten sou straffen, verclaerde d' Heer Generael haerliede, dat om dese boven verhaelde redenen, ende de groote en execiue oncosten van de schepen ende guarnisoenen, hij door last van de Heeren de bewinthebberen veroorsaeckt was geweest de saecke ter executie te leggen, ende dat sij oorsaecke waeren van haere eijgenne ruijnne ende verderff, haer voorenhoudende, soo sij ter goeder trouwen wouden handelen, hij haer in haer besit soude laeten blijuen, mits conditie dat se voor eerst 't gevluchte volck van de hoochte souden brengen, ende alles wat opt lant was in sijnne handen op de schepen souden gebracht worden, tot een erkentnisse van haer voorgaende misdaet ende alsdan nae de discretie van de Heer Generael daerinne soude worden gedisponeert.

D' Orangcaijs, de propositie van d'Heer Generael gehoort hebbende, hebben geantwoort, sij d' eenige oorsaecke van de voor verhaelde redenen niet en waeren 'alleene geweest, alsoo sij Orangcaijs in particulier waeren, ende in saecken van raede, den lande dienstich, mette gansche gemeente beraetslaecht wiert, vergaedert sijnde dickwils iders clachte gehoort hebben, als 
dat sij lieden bij de gecommitteerde van de Generael niet recht gehandelt en wierden, soo in de leueringhe van nooten ende foellije, als ook in de betaelinghe van de contanten, cleedinghe ende rijs, waerdoor sij veroorsaeckt waeren haere vruchten te leueren aen de Portugezen ende Javannen die van Maccasser ende andere plaetsen daer quamen. Belanghende het vergoottenne bloet, seijden ouer wedersijden geschiet te wesen, gelijck men in saeken van oorlooghen is gebruijckende, elcke parthije strijdende voor sijnne gerechticheijt, oock vreesende te verliesen de vrijheijt haeres geloofs, alsoo sij al reets vant eijlant Neyra hadden moeten vluchten ende op andere landen haer moeten generen. Voor soo veel aengaet de doot van den ouerleeden Admirael saligher met de sijnnen, bekende haer leet te wesen, ende als quallijcken gedaen, segghende sij het uwt haer selven niet en hadden begonnen, maer ter contrariën, van de voorgenoemde handelaers die haere vruchten quamen haelen, daartoe geraeden waeren, haer aendienende, soo wanneer sij sulcken een daet te wege conden brenghen als dan 't gemeene volck, die maer als slauen en waeren, lichtelijeken weder in 't besit van haere voorige vrijheijt souden geraecken, oock daer beneffens presenteerende haere hulpe. Belanghende de compste van Generael Laurens REaEL, ende sijnnen gepresenteerde vreede, mitsgaders sijnen tocht op haer lant ende haer deffentie daer tegens, seijden welgedaen te hebben ende niet gehouden en waeren tot vreede te verstaen, alsoo vooreerst int veroueren van ' $t$ eijlant Poullu ay bij d' Heer Commandeur JAN DIRRICKXsz 'T LAM ende die van sijnnen raede met haerlieden altsaemen op den derden Meij anno 1616 eenen vasten ende onverbreckelijcken peijs gemaeckt was; niettegenstaende dit verbont, den Gouverneur van Neyra DIRRICK PIETERSSEN vaN DEN zANDE ende den Luijtenant Gouverneur van Poullu ay ADRIAEN vaN DER DUSSEN denseluen hebben gebrocken, haerliede met haere kinderen ontbiedende, soo het fraeij ende bequaem weder was, op 't eijlant Poullu ay souden commen vermeijen; ende soot geen bequaem weder en was den Luijtenant Gouv ${ }^{r}$ soude op Neyra commen, alwaer hij mette Orangcaijs, haere kinderen, bij de Heer Gouverneur met malcanderen in alle vreede ende onderlinghe vrientschap souden handelen ende de kinderen begiften, om alsoo sij seijden het verbont te beter te bevestighen. Daer gecommen sijnde, de kinderen achterlaetende door onbequaemheijt des quaet weders, is 
haere willecomme geweest opt fregat de principaelste gevangen, int fort met een keten aent been, onder anderen den ouden CALLENBACKER aldaer als gevangennen overleden.

Om haer t' ontschuldighen van voorder mordadicheijt ende rebelie t'haeren laste gelecht, hebben ten tijde van HEYNDRICK DE WAETERFORT als president, hem vergunt een loogie te maecken op haer lant aen Orantatte, om dies te bequaemer te handelen; haere vruchten brenghende om te leueren, soo ist altoos 't' onpas geweest, ofte de foellie en was niet drooch, ofte de nooten en dochten ni-t, gelijek het ten lesten gebleecken heeft eenighe schepen daer sijnde, last gegeuen was aen $\mathrm{s}^{\mathrm{R}}$. GRYP ende JAN ADRIAENSEN, cooplieden, om deselue te ontfanghen, ' $t$ welk niet gesehiet en is, soo is gecommen eenen WATTERNEUI? Orangcaij van Labatacque, waeromme sij se niet en wouden ontfangen, seggende, sij sijn goet ende moghense aen niemant anders leueren als aen Ul., ende alsoo de voorschr. cooplieden deselue niet en wouden ontfangen, hebbende deselue opgehoopt ende in den brant gestecken. Verclaerde oock d' onse mette loogie niet te vreden sijnde, begonsten eenen vasten pagger ${ }^{1}$ daeromme te maecken, 't welck buijten alle redenen was, ten anderen, oock haer joncken ende prauwen ${ }^{2}$ die op haere coopmanschap waeren uwtvaerende, 't sij dat se beschiet hadden ofte niet, bij die van Poulli ay, als wesende Gouverneur wrLLEm vaN ANTSEN ende Cap ${ }^{n}$ vaN HoEVEN, seer leelijck mishandelt wierden, doodende haer volck ende roouende haer goet; belanghende de pretentie van eijgendom van de landen bij haer beseeten den Coninck van Ternaetten souden toebehooren, seijden daer geen kennisse van te hebben, maer ter contrarien bij haere ouderen ende out ouderen ouer veele jaeren in ruste onder de regeeringhe van de Orangcaijs waeren beseeten, die den $\mathrm{Co}_{0}$ ninck van Ternaetten in groote weerde waeren houdende, gelijek sijlieden oock deden, maer geen macht en hadde haer lant te transporteeren aen iemant anders om metten sweerde te winnen; omme dan tot een besluijt haer t' ontschuldigen van alle de voorgemelde bloetstortinghe ende oneenighheden, ende de aengegaene executie bij d' Heer Generael tot haere alle 
eeuwighe ruwijnne gedaen, verclaerden anders niet gesocht te hebben, als de vrijicheijt haeres geloofs, vreetsaemheijt op haer lant met vrouwen, kinderen ende slauen tot haeren dienste, omme de vruchten te innen, gesint sijnde deselue te verhandelen met die, diet op haerlieden met vrientschap souden versoucken. Aenmerckende nu haeren ongeluckighen staet, ten anderen sijde de propositie bij d' Heer Generael aen haer gedaen, vant besit van haer lant ende goederen, op conditie van de gevluchte ende anderen die int bosch waeren, in handen en gehoorsaemheijt van d'Heer Generael te leueren voor soo veel haer mogelijgk was, hebben 't selue belooft te doen. Tot breeder verseckeringhe van dese belofte ende onderlinghe vrientschap is besprocken, dat de Orangcaijs ouerleueren sullen haere kinderen die mannelijck sijn, in handen van d' Heer Generael, onder belofte van daermede te doen als eijgen, 't welck gevolcht is, ende d' Orangcaijs sijn weder naer lant gevaeren omt volck daertoe te bewegen.

De parthijen van de hoochte gecommen sijnde gelijck als vooren verhael, is het quartier afgestecken ende getrencheert, soo met steenen als eerdewerck, 't welek haest gedaen wiert, want veel handen maecken licht werck.

Den Orangcaij JARREN die aen lant was gebleuen ende niet in de vergaederinghe t' scheep en hadde geweest, heeft ondertusschen sijn debuoir gedaen, brenghende als nu ende als dan wat volcks aen, die nae boort gebracht wierden.

Daernae is den Orangeaij JARREN met den Sebander van Lonthor tsaemen naer Waeijer ende Demmer gevaeren met twee Orangbaijs ende eenighe tingans met soldaeten, ende hebben op den achtermiddach een partheije volckx, soo mans, vrouwen ende kinderen aengebracht, die mette tingans naer boort gevoert wierden, te weeten aen den Dragon.

Hier bouen is verhaelt, hoe dat de Orangcaijs t' schepe sijnde bij de Heer Generael, haere kinderen die mannelijeken waeren ouer moesten leueren, 't welck geschiet is. Eenighe geexamineert sijnde, omme te hooren ofte sij kennisse van eenighe saecken mochten hebben, soo isser onder anderen geweest den cousin van de huijsvrouw van joncker DIERICK, een Orangcaijs soone, die seijde in haer pitsiaeringhe ${ }^{1}$ geweest te hebben, ende aldaer ge-

1. بـإيا bitjâra, raadsvergadering.

Downloaded from Brill.come4/26/2023 05:22:12AM via free access 
hoort hadde, als dat sijlieden op dien nacht als de lampe gevallen was, haere meijninghe was geweest, om ons volck altsaemen omgebracht te hebben, voorder niet van meeninghe waeren den vreede te houden, maer ter contrarien haer te brecken daer sij best conden, 't sij aen den persoon van Generael, Gouverneur ofte andere soo sij best conden, ende alsdan de vlucht te nemen naer de custe van Ceram.

D' Heer Generael ende die van sijnnen raede, dit aldus verstaen hebbende ende door de voorgaende saecke quaet vermoeden hebbende, heeft d'Heer Gouverneur daervan geaduiseert, goede toesicht soude hebben, ten andere, alsoo den thijt verliep ende sonderlinghe geen voốrdeel en deden, geresolueerd waeren alle d' Orangeaijs, mitsgaders die van Sallamme, jonck ende out, $t$ ' schepe te doen commen 'tsij met minne ofte anders, hem de saecke met die van sijnnen raet recommanderende daerinne voorsichtelijeken te handelen.

D' Heer Generael is in persoone bouen op de hoochte van Sallamme gecommen om den wech te bereijden, om te beter tot sijnne voorgenomen resolutie te geraecken. Hij heeft de principaelste Orangcaijs bij hem ontboden; die gecommen sijnde, heeft haer vooren gehouden haere naelaeticheijt van de voorgaende belofte, ten anderen volghende het contrackt van vreede tsaemen aengegaen, bij haerliede niet en wiert geobserveert; seijde, sij lieden gehouden waeren de hoochte te verlaeten ende metter woonste om leeghe op strandt te commen wonen, alwaer sij tot dien eijnde alreets een parthije huijsen hadden gemaeckt, versocht ende begeerde dierhaluen dat 't selue sonder eenich wtstel soude volbracht werden; onder belofte van goede wacht te besorghen, op dat niemant aen haer ofte haere vrouwen, kinderen, goet ofte haue eenich leet soude doen, maer ter contrarien iets gebeurde ten hoochsten gestraft soude worden. D' Orangcaijs de propositie van de Heer Generael gehoort hebbende ende geenen beteren middel vindende alst volbrenghen, hebben dadelijeken ordre gestelt, laetende haere vrouwen, kinderen, slauen, slauinnen met meest haer goet om leeghe trecken alwaer de Comp van Cap $^{n}$ cornger lach, om haer te verseckeren. d' Heer Generael is voort doort quartier gegaen, 't selue besichticht hebbende, is weder in de tente commen rusten; metten anderen int breede beraetslaecht hebbende, is weder naer boort vertrocken aen 't schip Hol- 
landia, alwaer hij in deuotie d' uijtcompste van desen aenslach soude verwachten.

Den Gouverneur T' sionck metten raet hierop niet slaepende, hebben $\mathrm{Cap}^{\mathrm{n}}$ coINGET belast, het volck dat beneden was wel bijeen soude houden, ende soo wanneer het tijt was om aen te tasten hem daervan soude waerschouwen. Heeft voorder d' Orangcaijs ontboden mette inwoonders om met haerlieden te sprecken, die op den achtermiddach gecommen sijn, vooreerst haer aendienende alsdat d' Orangcaijs aen boort mosten vaeren om metten Heer Generael ende den raet te sprecken, over sulckx haere critsen ende geweer mosten afleggen, 't welck haer dadelijck is afgenomen; ende sijn alsoo bewaerder hant naer boort gesonden aen den Dragon ende Sirrickzee. De andere vrij-luijden ende ingesetenen sijn gevanckelijcken in den tempel gebracht ende aldaer de handen op den rugge gebonden; haer geldt dat sij bij haer hadden wiert haar genomen, meest van de officiers. Voorder wiert alles gevangen genomen, onder ende bouen, dat men conde becommen; de slauen en slauinnen die vluchtich waeren wierden door last van den Gouverneur weder geroupen, onder belofte van de gheene, die vrij willich weder quaemen, vrije luijden souden wesen, ende gheene slauen meer en souden sijn, waerdoor datter noch een parthije is gekeert ende bij d' onse gecommen.

'T geheele quartier ende lant aldus in roere staende, de passagien ende huijsen oueral beset, soo datter weijnighe ontquam, als doen quaemen de beste officiers ende soldaeten uwt, elck viel aent roouen ende plunderen, in plaetse van haer behoorlijcke plicht te volcommen; maer het out spreckwoort is: sijt ghij hoere ofte dieff, hebt ghij gelt ick heb u lieff, swijcht van mij, ick swijch van dij.

Ondertusschen is den Gouverneur met een parthije soldaeten met halue piecken naer 't huijs van Orangcaij JARREN gegaen, die oock al aen boort was, al waer hij noch eenighe Bandannesen heeft geuonden, waervan eenen was, die den tambour meijnde de reste te geuen, hem quetsende aen den hals, als noch een out Bandanees, die den Gouverneur meijnde te treffen; waerouer suleken beroerte quam, dat d' onsen dadelijeken vijff Bandannesen van Salamme dooden; d' ander vluchten met groote verbaestheijt, memorie. Onder andere een Bandannesche vrouwe, die heel blanck was ende chierlijcke ge- 
eleet, hebbende een gouden ketten om den hals, spronck van bouen aff van een seer hooge clippe tot in de leechte te bersten, lieuer dan sij haer in de handen haerder vijanden soude gevangen geuen. Dese dus gedoot ende

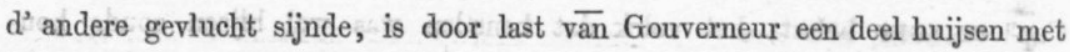
eenen tempel in brant doen stecken, 't welck schrickelijek om te sien was; daer wiert veel costelijekheijt verbrant, van cleederen, gout, silver, gemunt ende ongemunt, schoone porceleijnnen als andere. Den Gouverneur en wou niet toelaeten dat men iets berchden, ja dede selue de kisten die schoon ende wel gestoffeert waeren in den brant werpen, die menich soldaet sonder eenich perijckel verijckt souden hebben; patientie! dit gedaen sijnde is voorder gegaen naer 't quartier. Ontmoetende twee Adelborsten ende een soldaet, die hij te vooren gecommandeert hadde om eenighe huijsen in brant te stecken, haer vraegende van waer sij quaemen ende wie haer vervordert hadde uwt haer quartier te loopen, gauen hem voir antwoorde niets anders gedaen en hadden, dan haer bij den Gouverñ belast en was, ende 't selve volbracht hadden, oock haer seluen int plunderen ofte roouen niet en hadden besoetelt, alsoo men conden sien ende mercken. Den Gouverneur gebruijckende eenighe woorden, heeft den sergeant belast haerlieden gevanckelijcken in den tempel te brenghen, ende met scherpe wacht te versien; ' $t$ welck gedaen wiert. De gevangene Bandannesen, soo vrije als andere, wierden scherpelijcken bewaert ende s'anderdaechs noch eenighe bij gebracht, soo manspersoonen als vrouwen, die t' saemen nae boort bij d' andere gesonden wierden, die men seijde als doen sterck waeren op de schepen dertien hondert ende twee en twintich sielen, soo jonck als out. Hoe datter mede gedistribueert is bij die, die de macht hadden, ick sprecke van wechschencken als vercoopen, 'ten raeckt mij niet.

Den Gouverneur heeft den Heer Generael geschreuen 't misbruijjk van deese voorschreven soldaeten, 't welck hij ten quaetsten heeft aengedient; soo isser beschiet gecommen, als dat men mette executie voorts soude vaeren, volghende chrichsgebruijck. Cap $^{n}$ colve dit vernomen hebbende, hem seluen beswaert vindende, alsoo hij kennisse hadde van haere onnoselheijt, is gecommen bij JAN DE GRIBBE van Porcin, Luijtenant op den tocht, ende MathiU de back, Vendrich, nicolaes hiLlebrants, Adelborst, haer aendienende, soo sij noch een halff ure vertoefden, de sententie gewesen soude werden ende alle drije souden moeten sterven; soo hebben wij ons dade- 
lijcken vervoecht bij d' andere officieren, haer vermaenende; schuldich ende verplicht waeren voor haerlieden te sprecken, alsoo wij tsaemen verseckert waeren, gheen schult en hadden vant gheene haer ten laste geleijt wiert, maer dat 't selue geschieden soude door een groot misverstant. Sijn voorts gecommen aen de baleije daer den Gouverneur metten raet vergaedert waeren, alwaer de gevangenen alreede stonden om haere sententie te hooren; soo is bij ons eenen voetval gedaen, ootmoedelijcken biddende, d'Heeren souden belieuen de gevangenen te pardonneeren. De patienten verclaerden in haerer en onser aller tegenwoordigheijt niet gedaen te hebben, dan ' $t$ geene haer bij den Gouverneur was belast. Door veel menichvuldich bidden ende voet vallen van heele trouppe, isser bij den raet geordonneert drije briefkens te trecken ende die 't lot viel soude hanghen, 't welck geschiet is. Soo is door trecken 't lot op JAN VAN THIELT gevallen, den joncksten van drijen. De twee adelborsten sijn dadelijcken ontslaeghen ende den anderen weder in den tempel gebracht ende bewaert.

Voorder heeft den Gouverneur met twee Compe, JAN vaN HOEvEN ende JAN COINGETS, noch eens naer de hoochte eenen tocht gedaen omme de gevluchte Bandannesen van Lonthor ende d'andere eens te gaen besichtigen. Bouen tot bij haere vasticheijt commende, is wederomme gekeert, in brant steckende alle de huijsen ende gehuchten, die op de geheele passagie stonden ende alsoo weder om leeghe gecomen int quartier. Dien avont sijn wij gewaerschout ons gereet te maecken om tsanderdaechs te vertrecken naer Waeijer ende Demmer met de tingans. Des morgens voor ons vertreck sijn wij andermael noch eens bij den Gouverneur/ende den raet gegaen, ootmoedelijcken versouckende voor den gevanghenen sijn pardon, die wij verstaen hadden dien dach ter executie gebracht soude worden; hebben andermael eenen voetval gedaen ende gebeden dat d'Heer Gouverneur soude belieuen te prefereeren gratie in plaetse van riguer van justitie, ten anderen soude belieuen in te sien sijnne jonckheijt van jaeren ende oock d' onervaerentheijt van d' oorloghe ende chrichs gebruijck; gaff voor antwoorde daer geen gratie en was, maer most steruen; waerop oock antwoorde Cap ${ }^{\mathrm{n}}$ JAN JANSSEN GORcuM, dat hij den doot genouch verdient hadde ende gratie genouch geschiet was aen d' ander twee, die wij verbeden hadden. Weijnich docht hij op sijnnen getrouwen dienst die hij de Compaignie op Batavia gedaen hadde, 
Godt betert; voorder seijde, dat elck hem gereet maecken soude om te vertrecken mette tingans daer wij bescheijden waeren, aenmérckende ons voorbidden niet helpen en conde. Sijn vertrockén, verhoopende sijnne jonckheijt verschoont ende aengesien soude worden.

Soo sijn wij met een groote parthije muskettiers, onder 't beleijt van Gouverñ, mette tingans, eenighe corre-corren ende prauwen met swarten, vertrocken naer Waeijer. Daer gecommen sijnde, hebben den tempel met alle de huijsen in brant gestecken ende alles gedestriueert, maer geen volck gevonden als een out man die sieckelijck was, die d' onse het hooft afsloeghen ende op eenen staeck aent strant setten.

Hier vooren hebt ghij gehoort, als dat door last van d' Heer Generael op Waeijer een ondercoopman JAN DE BIE was gelaeten met een assistent ende jongen, om opsicht te hebben dat haere vasticheijt aff geworpen souden worden. Daer gecomen sijnde, hebben hem doot gevonden opt strandt, seer lelijcken mishandelt, ende den jonghen seer lelijcken gequest, die soo haest als hij ons vernam bij ons is commen cruijpen, seggende de Bandannesen niet beter en wisten ofte hij en was doot. Voorder verhaelde ons, hoe dat den assistent bouen op den hooghen berch gehangen was, den ondercoopman om leeghe gebracht hadden ende opt strang gedoot, ende dat dit geschiet was doen de Badannesen van Salamme gevlucht quamen, seggende dat de Hollanders het op Salamme al vinghen ende doot sloeghen, ende alsoo sijn die van Waeijer ende Demmer gevlucht naer den hooghen berch bij d' andere; daer was groote opspraecke onder 't volck, seggende, men hadde dese personnen wel bij tijts connen waerschouwen, om bij d'onse te commen, eer men de Bandannesen alsoo aentasten, want Waeijer ende Demmer waeren mede in den vreede besloten. Watter van is, sij sijn doot, Godt salt oordeelen.

Aldus op Waeijer alles verbrant ende vernielt hebbende sijn vertrocken naer Demmer, sendende 't doode lichaem naer Sallamme ende is daer begrauen, op Demmer ist oock al verbrand ende verwoest, den tempel $\overline{\text { nn }}$ alle de schoone huijsen. Het doet mij wee te verhaelen de verwoestinghe ende de schade die geschiet is op dese twee plaetsen, want ick in mijn leuen nooijt schoonder noch plaijsanter gesien en hebbe, van woonplaetse als van vruchten, seer bequaem geplant, soude te lanck vallen te verhaelen; dan en 
wiert geen buijt gevonden op dese plaetsen, want sij tijts genouch gehad hebben om te vluchten. Alsoo sijn wij weder vertrocken mette tingans ende op Sallamme gearriveert, alwaer wij bevonden JAN VAN THIELT gerecht was, aen eenen manguus ${ }^{1}$ boom. Ons wiert gesecht dat Capitejjn Gorcum seer nerstich bij de executie was, want hij maeckte selven den strop, ende smerde hem met een stuck speckx, omdat den swarten beul geen goede handelinghe daervan hadde; den patient siende den doot voor ooghen, nam Godt tot getuijgen dat hij onschuldich was, ende beriep sijnne rechters ten joncksten daeghe voor 't oordeel Godts.

Ten selven daeghe, naer den middach, isser eenen Jappander van sijn schildwacht naer een jonck hoen geloopen om te vatten, niet seer verre, waer over een sargant gecommen is die hem daerover slouch; hij heeft sijn geweer getrocken ende naer den sargant gehouden, ende den sargant van gelijcke, questende den Jappander in de hant. Is den Jappander daerover gevangen ende 's anderdaechs gehanghen.

De Comp van Capiteijn corNaEt was gecommandeert om met tingans naer Rosageijnne te vaeren, om te besichtighen ofte daer eenighe gevluchte Bandannesen mochten sijn; maer is door den stercken wint naer middach weder gekeert. Wij waeren wel versekert, sij ons aldaer geen resistentie en conden doen, door dien wij te vooren haer hadden haere macht benomen. Geschieden om andere redenen.

Tot op den $29^{\text {sten }}$ April de saecke dus verre gebracht hebbende, is bij den Heer Gouverneur ende raet belast, alle de fortificatie bij ons gemaeckt af te werpen, 't welck met alle vlijt gedaen wiert, mette gansche meenichte. 't Selve gedaen sijnde isser een parthije muskettiers gecommandeert, die voor aen de hoochte vant geberchte trocken om te besichtighen, alsoo wij op ons vertreck stonden, ofte de gevluchte Bandannesen niet af en quamen van haere hoochte om ons te beschadighen. Ondertusschen staecken wij alle de huijsen in brant die op Sallamme waeren, 't welck die van de hoochte seer gemackelijcke aensaeghen tot haerder groot leetwesen. De parthije gewaerschout sijnde, is bij ons gecommen, ende soo met gemack naer de strant vertrocken, alwaer de schuijts mette boots ende tingans gereet laeghen. De

2 Lغن mangga, ecne smakelijke vrucht. 
leste Comp ${ }^{e}$ afcomende, heeft den grooten tempel in den brant gesteeken mette balleije, daer den Gouverneur metten raet ende een Comp ${ }^{\circ}$ soldaeten op hadden gelogeert. 't Verderff van de schonne vruchtboomen was seer groot. Om leeghe gecommen sijnde, hebben ook alle de nieuwe geboude huij. sen in brant gestecken, ende alsoo in de schuijts, tingans, ende boots gegaen, ende elck naer sijn quartier, garnisoen ende schips boort vertrocken, waer over wij altsaemen seer verblijt waeren.

D' oorsaecke van onse blijtschap was niet dat ons verdroot, ons lijff ende leven geemploijeert te hebben ten dienste ende proffijt van de Heeren meestcrs de Bewindhebberen der vereenichde Oost-Indische Comp ${ }^{\circ}$, wiens suigecten ende dienaers wij sijn in alle getrouwicheijt, bereijt sijnde lijff ende leven te laeten ten dienste ende proffijt van haere Ed.; maar 't is te beclaeghen dat wij hier te lande van de geene die alhier in regeeringhe, de goede niet te naer gesprocken, gesonden ende gestelt worden, soo weijnich geacht sijn. Onse meeste blijtschap was, dat wij aldaer van haer vloucken, slaeghen, grooten honger ende dorst, die wij gedurende dese weijnighe daeghen geleden hadden, verlost wierden. Onder anderen gebruijckte den Gouverneur T'sioncK dese woorden aengedient sijnde van eenen quartiermeester als dat hij ende sijn volck geen eten en hadden: laet de honden steen eeten ende drincken dat sij bersten. JAN JANSEN GORCUM, 't selve oock aengedient sijnde van seecker officieren van soldaeten, gaff haer deselue antwoorde, waerover hij GoRCuM in groote woorden gerocht is tegens Cap ${ }^{\mathrm{n}}$ JAN vAN HOEveN; wierden geschieden van den Gouverneur, memorie. Aldus de Bandannesen binnen de schips boorden gevanghen sijnde, sijn als nu ende alsdan de principaelste met parthijen bij d' Heer Generael ende raeden verhoort ende geexamineert geweest.

$\mathrm{Cap}^{\mathrm{n}}$ coINGET is met sestich muskettiers naer Rosageynne getrokken om aldaer to blijven voor eenen tijt, maer en heeft er geen volck gevonden.

Op den vierden Meije isser een groote parthije muskettiers naer de hoochte getrocken, lanckx Orantatte, vergeselschapt metten Heer Gouverneur, Cap" schot, Cap ${ }^{\mathrm{n}}$ COLVE, NICOLAES GURRY, Luijtenant, ende WYNANT BRANTS, $\mathrm{Cap}^{\mathrm{n}}$ DE Nova, omme de hoochte van dese sijde te besichtighen. Bouen gecommen sijnde tot onder haere vasticheijt, hebben de swarte op d' onse geschooten met bassen ende musketten. Cap ${ }^{n}$ colve die vooren was, heeft 
hem mannelijcken gequeten; geen voordeel siende, door lanckdurich schieten ende schermutselen, heeft moeten wijcken; Cap ${ }^{\mathrm{n}}$ scнот heeft hem verlost, die wiert ter plaetse dootgeschooten, voorder sijnnen vendrich MAERTEN VAN DE WELLE het been onstucken ende wiert daernae van de Bandannesen 't hooft afgehouwen, den Luijtenant NICOLAEs GURRY heeft de Comp ${ }^{e}$ van scнот verlost, alsoo den $\mathrm{Cap}^{\mathrm{n}}$ doot was ende een parthije van sijn volck gequest; heeft hem int aencommen seer wel gepresenteert met sijn volck, maer alsoo de passagie seer smal ende priculeus was, ende niet bequaemelijcken en conden bij commen, oock met schieten geen voordeel en saeghen, is geraetsaem gevonden te vertrecken. Den Capitein wYNANTS BRANTs, die seer voorsichtelijeken handelde, int aensien, bleef achter, om $d$ 'eerste te veesen int vertrecken. Alsoo is de parthije wedergekeert. Den vijant heeft hem dapperlijck geweert ende d'onse vervolcht tot bij Orantatte, den Gouverneur die om leeghe op het strant gebleuen was, is hiervan geadverteert; heeft belast dat se afcommen souden ende de gequeste wel besorghen.

In dit besichtighen van de hoochte sijn thien ofte elff doode gebleuen ende wel in de veertich gequeste, voorder is elk weder vertrocken bij de sijnne. De Heer Generael dit vernomen hebbende, die ondertusschen wat Pynan hadde gegeten, gaf voor antwoorde, haer geen voorder last gegeuen en hadde, dan om de vasticheijt van den vijant te ontdecken ende niet om te slaen.

Voorder is den Heer Generael metten raet vergaedert, hebben geresolueert een eijnde van de saeken te maecken. Hebben vooreerst afgevoordert d' Heer FrEDERICK houtMaN, out Gouverneur ende eersten Raet van Indiën, om als Gouverneur te commandeeren in de Molluques, ende is vertrocken naer Malleije. Als noch is vertrocken d' Heer wILLEM vaN aNTSEN Raet van Indiën naer Jacquatra. Ten anderen 't vernieuwen van cooplieden, ondercooplieden, Cappiteijnen, Luijtenants als anders. Heeft oock diversche vereert met schonne schenckaigen, soo gelt, goet, slauen ende slauinnen, bassen, corre-corras ende prauwen.

De sáecke van de gevanghenne Bandannesen, die ten deele de principaelste geëxamineert waeren, is bij der handt genomen, onder andere tot ses en veertich int getal, meestal Orangeaijs, voorts vrije luijden die haeren staet houden beneffens d' Orangcaijs, in saecke van Raede, ende sijn ge- 
condemneert ter torturre om seckerheijt te weten van haere voorgenomen conspiratie, volghende de bekentenisse van den cousin van de huijsvrouw van joncker DIRRECK, als vooren verhaelt.

Omme dit te effectueren sijnder als rechters toe geordonneert den Gouverneur MaRTen 'T' SIONCK, JAN JANSSEN GORCUM, JAN vaN HOEven, Cap ${ }^{\mathrm{n}}$ voGHEL ende meer mij onbekent. De geordonneerde plaetse van de torturre opt schip Dragon ende Sirricksee; op den Admirael, 't schip Hollandia, waeren acht Orangcaijs gebracht ende daer naer weder op Sirricksee; daer ontcleet werdende is bij haer twee gouden kettenen geuonden ende bij den Gouverneur in bewaerder hant (genomen).

Terwijllen datt men met deese saecke besich was heeft d' Heer Generael den ouden $\mathrm{Cap}^{\mathrm{n}}$ ттто, een groot Orangcaij, met sijn soone ende volck die met den Generael van Amboyna gecommen waeren, met een Orangcaij naer Sallamme gesonden, om met de gevluchte Bandannesen, die op de hoochte waeren, te sprecken, haer presenterende den vrede; maer 't was al te vergeefs, sij bleuen bij haere voorgenomen resolutie. Dit geschiede tot diuersche reijsen, maer 't was ende bleef al 't selue.

Daernaer is noch gesonden den ouersten Orangcaij ende paep van Poulluron ter seluer oorsaecken, haerlieden veel schoons presenteerende; maer sij en wouden van de saecke niet handelen. Hij is meermaelen derwaerts geuaeren, gaven hem ten lesten voor antwoorde, metten Generael niet te doen en hadden, ende dat hij hem niet vervoorderen en soude daar meer te commen, ofte sij wisten wat sij met hem te doen hadden.

D' executie vant pinnighen aen de voor verhaelde gevanghenne Bandannesen heeft sijnen voortganck gehadt, dewelcke seer rigoureus heeft toegegaen. Den fiskes heeft haerlieden alle haere delickten voorgelecht, soo oude als nieuwe, ten deele als voren verhaelt, verstaen hebbende uwt den mont van een persoon die onmondich was, als wesende bloetrrient van joncker DIRRICK Orangcaij; waer ouer datter twee Orangcaijs bij haer ontkennen blijuende doot gepijnicht ende ouer boort geworpen sijn. Wij en hebben nooijt connen verstaen dat sijliede iets tot haeren laste gelecht bekent hebben, maer ter contrariën geprotesteert van inuocencie ende niet anders betracht en hadden; blijckende bij haere voorgaende acte van deligentie int aenbrenghen van haer volck, den vreede mette Hollanders gemaeckt in 
aller getrouwicheijt te houden staen, bereijt wesende daer bij te leuen ende te sterven.

Eijndelijcken soo sijn sij bij d' Heer Generael ende den raet, op den achtsten Meije anno 1621, gecommandeert ter doot, welcke executie geschiet is opt eijlant Neyra, ter sijde van 't casteel Nassauv, als volght.

Vooreerst sijn binnen 't casteel gebracht vier en veertich gevangenen, waervan achte besonder sijn gestelt, overste Orangcaijs, die, soo men seijde, de catte de belle aengedaen hadden; d' ander sijn bij den anderen gebleuen, gelijck eenen troup schaepen. Buijten 't fort was een ront perck gemaeckt van bambousen, wesende groote rietten, ende sijn aldaer gebonden met coorden binnen gebracht, wel beset met garnisoen; haere sententie is gelesen geweest tot haeren laste, in forme als vooren verhaelt, als dat sijlieden gestaen souden hebben naer 't leuen van d' Heer Generael ende bontbreeckers waeren van den gemaeckten vreede. Voor 't lesen van de sententie wiert verboden op lijfstraffe, als dat hem niemant vervoorderen en soude int perck te commen, dan alleen paeter ende maeter.

De gecondemneerde patienten in 't perck staende, waeren der geordonneert ses Japponesen, die met haere scherp snijdende sweerden voor eerst de acht principaelste ende grootste Orangcaijs te midden door hebben gehouden, daernae ' $t$ hooft aff ende voorts in vier quartieren gesmeten; de andere ses en dertich, het hooft aff ende voorder in vier quartieren als d' eerste, welcke executie seer wreedelijeken was om aen te sien. Sij stierven in alle stilheijt sonder eenich gewelt te maeken, alleenelijck wasser eenen die in onse Duitsche taele vraechden, mijn Heeren en isser dan geen genaede, maer 't en mocht niet helpen.

Geduerende dat dit recht geschiede, soo heeft het soo schrickelijcken gereghent, dat het een ider verwonderde. De hoofden ende quartieren van de geëxcuteerden, wierden op bambousen gestelt ende gehanghen. Aldus sijn sij gepasseert; Godt woeet wie recht heeft.

Dit, 't welck ons altsaemen dochte, als willende Christennen genaempt worden, volbracht sijnde, sijn met verbaestheijt ider vertrocken nae sijn quartier glieen behaeghen hebbende in sulcken coophandel.

De Heer Generael ende raeden, geen middel vindende om de gevluchte Bandannesen van de hoochte te connen crijgen, hebben der cleijnne swaericheijt daerin gemaeckt, gebruijekende daertoe deese redenen. 
Vooreerst, alsoo sij een groote menichte op de hoochte waeren ende seer quaelijcken voorsien van prouisie, haer selue soude matteeren.

Ten tweeden, geen corre-corren ofte prauwen en hadden om te vluchten, doordien wij deselue meestal hadden verouert ende onstucken gesmeten.

Derde, gheen macht en hadden om teghen d' onse te opposeren ten aensien daer veel vrouwen ende kinderen waeren.

. 't Vierde, door den honger ende commer, lichtelijeken eenighe oneenichheijt soude moghen ontstaen.

Dit ende meer andere redenen in consideratie genomen hebbende, is gecommandeert 't schip den Eenhoorn ten ancker te gaen liggen voor Sallamme 't schip Enckhuysen in 't incommen van Lonthor, 't Waepen van Jacquatra sonder steuen voor Waeijer ende Demmer, de Galleije aent Vrouven eijlant, de tingans met parthijen rontom het lant te vaeren om alsoo haere vlucht ofte eenighe toeval te beletten.

Op Lonthor ende andere plaetsen belast scherpe wacht te houden, 't schip den Dragon, door last, is vertroẹken mette resteerende gevanghenen Bandannesen naer Jacquatra, vergeselschapt met 't schip Schiedam ende 't Postpaert, dienende tot convoije.

IsEBrant cornelissen, Capiteijn ende schipper van 't schip Hollandia, Admirael van de vloote, daer d' Heer Generael opvoer, is belast hem gereet te maecken, $d^{\prime}$ ander van gelijeke.

Den grooten Orangcaij en paep van Poulluron heeft sijn afschiet genomen van Heer Generael, begeerende voor sijn vertreck tot een teecken van vreede eenige eerschoten, 'twelck gevolcht is tot seven toe, ende is alsoo vertrocken naer Poulluron.

Op den veerthiende Meije $A^{\circ}$. 1621 is den paeijs gepubliceert ende de artickelen beëdicht tusschen de gansche menichte van Poulluron ende de gedeputeerde, van d' onse bij d' Heer Generael daertoe gecommitteert.

Den vijfthiende Meije heeft d' Heer Generael in 't casteel Nassaun sijn schiet maeltijt gehouden, voorder den Gouverneur met die van sijnnen raede de saecken ten hoochsten recommandeerende.

Den sesthiende van Meije 's morghens, sijn wij vertrocken naer Itto vergeselschapt met 't sehip Amsterdam, Nieuvo Seelant ende Sirricksee. Int uwt- 
vaeren verongelijekten 't schip Orainges bouchspriet achter tegen onse regelijnghen, op de rhede liggende, adieu.

Op den $12^{\text {den }}$ Jullij anno 1621 , sijn wij des avonts gearriveert op de 'reede voor de stadt ende 't casteel Batavia, liggende op.'t coninckrijck van Jacquatra. Den $13^{\text {den }}$ ditto is d' Heer Generael aen lant geuaeren. Daer wiert tot, vereeringhe soo van de schepen als van 't casteel seer veele geschooten, daer wort menich kinderbedde gehouden dat soo veel niet en cost.

Geduerende onse lichdaeghen is alhier een tingan gearriveert van eijlanden van Banda, afgevoordert bij d' Heer Gouverneur MaRTen t' sioncK met brieven aen den Heer Generael, mentie maeckende vant veroueren van de hoochte ende vlucht van de Bandannesen als volght.

Vooreerst isser eenen Orangcaij commen overloopen, seggende die van bouen geen cruijt, lont, nochte loot en hadden ende van honger vergingen, bereijt was den pat te wijsen.

De Heer Gouverneur de kennisse hebbende, is met vier Comp daer naer toe getrocken. Boven gecommen sijnde soo en heeft den vijant anders geen resistentie gedaen, als werpende met steenen, saga-saga ende assagaijen, $d$ ' onse daer op schietende, 't welk een cleijn ure duerde, sijn sij van den berch gevlucht, sijn alsoo bouen gecommen, vindende 15 a 16 bassen. Voorts geenen buijt, alleenlijck een blinde vrouwe. Voorder hebben alle de muraige ende pallesaeden onverre geworpen ende sijn daer twee nachten gebleuen, maer door de groote coude moesten vertrecken. Int vertrecken staeken wel 16 a 1800 huijsen in brant, vonden oock wel 6 a 700 hunner graeuen, meest van coude ende ongemack gestorven. Dese hooehte is bouen wel een ure gaens int ronde, ende van beneden aen te sien, is als eenen spitsen thooren.

De Gouverneur is mette parthijen vertrocken naer Waeijer ende Demmer omme de gevluchte te vervolghen, daervan sij noch gevanghen creeghen 70 a 80 personen, soo out als jonck; de resteerende waeren gevlucht met corre-corren die sij van nieuws gemaeckt hadden. Onder anderen int vluchten isser een verdroncken, daer ouer de 250 sielen inne waeren, alsoo de gevanghenen getuijchden.

De gevanghenen wierden naar Sallamme gebracht. Op den wech wiert er 10 a 12 dootgeslaeghen, die niet volgen en conden; de resteerende naer Neyra. 
Op Neijra commende heeft d' Heer Gouverneur een blij maeltijt gegeven ende alle de soldaeten op de vier punten verdeelt, de stucken doen lossen, voorder haer alle de volheijt van Spaenschen wijn gegeuen en ider man ses realen van achten.

Dese tingan daerop commandeerde cLAEs wEERTS met derthien roeijers, sijn bij d'Heer Generael vereert, CLAEs WEERTs veertich realen, den stierman veertieh, den quartiermeester vijffthien, $d$ ' ander elck acht realen van achten. 